\title{
Down-Regulation of a Profibrotic Transforming Growth Factor- $\beta 1 /$ Cellular Communication Network Factor 2/Matrix Metalloprotease 9 Axis by Triamcinolone Improves Idiopathic Subglottic Stenosis
}

\author{
J. Humberto Treviño-Villarreal, ${ }^{*}$ Justin S. Reynolds, ${ }^{\star}$ P. Kent Langston, ${ }^{\dagger}$ Andrew Thompson, ${ }^{\ddagger}$ James R. Mitchell, ${ }^{*}$ and \\ Ramon A. Franco, Jr${ }^{\star \S}$
}

From the Department of Molecular Metabolism, * Harvard T.H. Chan School of Public Health, Boston; the Department of Immunology, ${ }^{\dagger}$ Harvard Medical School and Evergrande Center for Immunologic Diseases, and the Dana Farber Cancer Institute/Harvard Medical School Rodent Histopathology Core Facility, ${ }^{\ddagger}$ Harvard Medical School, Boston; and the Division of Laryngology, ${ }^{\S}$ Department of Otolaryngology, Mass Eye and Ear and Harvard Medical School, Boston, Massachusetts

Accepted for publication May 7, 2021.

Address correspondence to Ramon A. Franco Jr, M.D., Mass Eye and Ear, 243 Charles St., Boston, MA 02114. E-mail: ramon_franco@meei.harvard. edu.

Idiopathic subglottic stenosis (iSGS) is a chronic progressive low-grade fibroinflammatory disease of the subglottis that primarily affects women between the third and fifth decades of life. ${ }^{1}$ Clinically, iSGS is characterized by progressive fibrotic narrowing of the airway, causing exertional dyspnea and significantly reducing the quality of life. ${ }^{2}$ Histologically, there is evidence of a fibroproliferative process with disorganized deposition of extracellular matrix (ECM), resembling keloid fibrosis. ${ }^{3}$ This observation founded our rationale of treating patients with iSGS with repeated local steroid injections, similar to how skin keloids are treated. ${ }^{4}$ The established treatment protocol, denominated serial intralesional steroid injections (SILSIs), is

\footnotetext{
Disclosures: None declared.

Current address of J.H.T.-V., Endocrinology Service, Department of Internal Medicine, University Hospital Jose Eleuterio Gonzalez and School of Medicine, Universidad Autónoma de Nuevo León, Monterrey, México.
} 
defined as a series of five to six steroid injections, each one separated by 3 weeks, directly into the stenosed-fibrotic subglottic mucosa. ${ }^{5}$ In-office SILSI significantly improved breathing and clinical outcomes to the same level as endoscopic surgery, as evaluated by forced spirometry, with durable results for several years, without the need for surgical intervention. ${ }^{6-8}$

The mechanism by which SILSI works as well as the molecular bases underlying iSGS progression are largely unknown. SILSI represses fibrosis with durable results, suggesting the involvement of steroid-sensitive pathways implicated in the development of iSGS. Studies of keloid fibrosis and other nonautoimmune idiopathic diseases, such as cardiac, liver, or kidney fibrosis, have implicated members of the transforming growth factor (TGF)- $\beta$ family as key regulators. ${ }^{9-12}$ In fact, steroids like triamcinolone improve skin fibrosis by down-regulating TGF- $\beta 1$ expression, ${ }^{4}$ suggesting that SILSI might work via the TGF- $\beta 1$ pathway. However, the role of TGF-1 in iSGS pathology has not been investigated comprehensively.

TGF- $\beta 1$ is a master regulator of fibroblast function, ECM production, and ECM remodeling, playing key roles in organogenesis, development, and wound healing. ${ }^{13,14}$ TGF$\beta 1$ is produced by many cell types in an inactive form bound to the latency-associated peptide, from which it is released following proteolytic activation by surface plasmin and furin convertases. ${ }^{15,16}$ Once free, TGF- $\beta 1$ binds to the TGF$\beta$ receptor I, through which it controls fibroblast activation and ECM synthesis through the activation of SMADdependent and SMAD-independent pathways. ${ }^{17}$ In the SMAD-dependent/canonical pathway, ligand engagement to TGF- $\beta$ receptor I results in the phosphorylation of SMAD2/ 3 , which, after binding to SMAD4, migrates to the nucleus where in fibroblasts it stimulates the production of ECM. Alternatively, activation of the SMAD pathway by TGF- $\beta 1$ primes fibroblast to differentiate in myofibroblasts, which are a specialized, terminally differentiated, $\alpha$-smooth muscle actin-expressing contractile cell subset that actively participates in the production of the ECM, especially during scarring and/or wound healing. ${ }^{10,18}$ More importantly, dysregulation of TGF- $\beta 1$ signaling can increase the number and the activation state of myofibroblasts, which, in turn, promote fibrosis by producing abnormally high levels of ECM proteins. ${ }^{19}$

Another way by which TGF- $\beta 1$ controls the ECM composition is by suppressing the expression of certain matrix metalloproteases (MMPs) involved in matrix remodeling, including MMP1 and MMP9. ${ }^{20-22}$ Furthermore, TGF- $\beta 1$ can amplify its own effects through the engagement of alternative pathways by stimulating the production of other profibrotic mediators. ${ }^{23,24} \mathrm{~A}$ wellknown mediator that acts in this manner is the cellular communication network factor $2(\mathrm{CCN} 2),{ }^{22}$ a mitoattractant factor that simulates the proliferation and cell adhesion capacity of fibroblasts, chondrocytes, and other related mesenchymal stromal cells. ${ }^{25-27}$ More importantly, dysregulation of CCN2 leads to idiopathic fibrotic disease states in kidney, heart, and skin that resemble those generated during the dysregulation of TGF- $\beta 1$ signaling. ${ }^{23,24,28}$ Whether CCN2 and/or dysregulation of ECM remodeling via metalloprotease levels contributes to iSGS development is not known.

Herein, the beneficial clinical response to SILSI in iSGS patients was used to investigate the profibrotic mediators present at baseline, how they change throughout steroid treatment, and to identify mediators of importance to iSGS development. A putative profibrotic axis involving TGF$\beta 1$-induced CCN2 induction and MMP9 repression was identified that appears to be implicated in iSGS development, and is the molecular target of triamcinolone when administrated by SILSI.

\section{Materials and Methods}

\section{Human Study and SILSI Treatment}

\section{Study Approval}

This prospective study was approved by the Partners Internal Review (protocol 2019P000847). All patients received a detailed explanation of the study and signed informed consent after agreeing to participate.

\section{Recruitment}

Seven patients with newly diagnosed iSGS were recruited between May 2016 and June 2018. All patients had untreated fibrotic narrowing of the airway and had severe symptoms that required intervention. The patients had no history of trachea-laryngeal trauma or recent intubation or active airway infections, were all proteinase 3 antineutrophil cytoplasmic antibodies negative, and presented no clinical, biochemical, or serologic evidence of an underlying autoimmune process.

\section{Baseline Evaluation}

The initial clinical evaluation before SILSI consisted of forced spirometry to assess the baseline airway functional capacity, and a laryngoscopic visual inspection of the airway to assess the magnitude of the disease state. Forced spirometry was performed with an open-circuit, hand-held digital spirometer (Microloop Spirometer; Vyaire Medical, Mettawa, IL). The parameters measured were peak inspiratory flow, peak expiratory flow, and the peak expiratory flow percentage (PEF\%). The PEF\% is a value normalized to the patient's age, sex, height, and weight. For visual inspection, we anesthetized the airway and nasal cavities with lidocaine, and passed a flexible distal-chip nasolaryngoscope through the nasal cavities to visualize the larynx and trachea, placing special attention to the extent of the scarring, presence and extent of erythema, size of the subglottic narrowing, and involvement of the true vocal folds, arytenoid cartilages, and the posterior glottic and subglottic airways. 


\section{SISLI Injections}

The initial procedure took place in the operating room, where we performed suspension microlaryngoscopy with a large-bore operative laryngoscope using a humidified supraglottic high-frequency jet ventilator to maintain oxygen saturation (Monsoon III; Acutronic Medical Systems AG, Hirzel, Switzerland). Before injecting steroids, biopsies of the subglottises were taken using upturned and straight large cupped forceps as follows; for gene expression, the tissue was placed in a prelabeled $1.5-\mathrm{mL}$ sterile Eppendorf tube and immediately snap frozen by submerging it into a liquid nitrogen bath. Another sample intended for histology was collected in a similar manner. For primary fibroblast isolation, the tissue was placed in sterile $2.0-\mathrm{mL}$ microcentrifuge tubes containing $1 \mathrm{~mL}$ of sterile Dulbecco's modified Eagle's medium/F12 supplemented with 20\% cosmic calf serum (Hyclone; Cytiva, Marlborough, MA) and $2 \times$ antibiotics on ice until processing. For routine pathologic evaluation, the tissue was placed in a plastic jar containing $10 \%$ formaldehyde in phosphate-buffered saline (PBS), and fixed for 12 hours, before processing.

After tissue harvesting, we removed the remaining scar tissue to adequately open the airway. We used a $38-\mathrm{mm}$, 25 -gauge needle to inject a triamcinolone, $40 \mathrm{mg} / \mathrm{ml}$, with $1: 10,000$ epinephrine solution into the affected areas. A total of 3 to $5 \mathrm{ml}$ was injected ( 120 to $200 \mathrm{mg}$ of triamcinolone) during the surgery. Each injection of steroids was followed by mechanical dilation to expand the lumen and compress the steroids into the surrounding tissue with a 16- to $20-\mathrm{mm}$ CRE balloon (Boston Scientific, Natick, MA). This was repeated two to three times. An epiglottic sample was collected as the final step in the operative intervention, and the pieces were preserved and allocated as above.

In-0ffice Awake Interventions: Forced Spirometry, Harvesting Subglottic Tissue, and Injection of Triamcinolone

Subjects were seen at days 21 and 42 after surgery in the office for forced spirometry and for intralesional steroid injections. On these occasions, we began our outpatientawake encounter with forced spirometry to obtain the peak inspiratory flow, peak expiratory flow, and PEF\%. Then we performed flexible endoforceps biopsy of tissue followed immediately by awake injection of triamcinolone as follows. After trans-tracheal injection of $2 \mathrm{ml}$ of $4 \%$ lidocaine and topical intranasal application of $2 \%$ lidocaine with $0.025 \%$ oxymetazoline, the flexible distal-chip nasolaryngoscope with the 2-mm working channel was passed down to the level of the larynx. A 1.8-mm endoscopic biopsy forceps (Radial Jaw 4; Boston Scientific) was used to remove one or two pieces from the previously treated area of stenosis. These pieces were immediately placed into a $1.5-\mathrm{ml}$ Eppendorf tube that was placed in a liquid nitrogen bath to snap freeze the tissue. Immediately, a $200-\mathrm{cm} 25$-gauge flexible endoscopic retractable needle (Interject Contrast, 1.8-mm diameter; Boston Scientific) that had been primed with triamcinolone, $40 \mathrm{mg} / \mathrm{ml}$, was placed down the working channel of the nasolaryngoscope. A total of $1.7 \mathrm{ml}$ of triamcinolone, $40 \mathrm{mg} / \mathrm{ml}$, was injected $(68 \mathrm{mg}$ of triamcinolone) into the area of the subgottic stenosis. ${ }^{5}$ Although subglottic samples for this study were taken only before the second and the third round of SILSI, the patients continued this regimen of injections until they completed a total of six injections overall.

\section{In Vitro Studies}

\section{Isolation of Epiglottic and Subglottic Primary Fibroblasts}

Tissue samples were transported from the operating room to the laboratory in $2.0 \mathrm{~mL}$ of preservation media placed, consisting of Dulbecco's modified Eagle's medium (ThermoFisher, Waltham, MA), fetal bovine serum 20\% (ThermoFisher), and $2 \times$ antibiotic/antimycotic (from a $100 \times$ stock concentration; ThermoFisher; catalog number 15240062) on ice. Processing began by placing the tissue samples in $5 \mathrm{~mL}$ of $37^{\circ} \mathrm{C}$ prewarmed digestion buffer, consisting of dispase grade II $(1 \mathrm{U} / \mathrm{mL}$; Roche, Wilmington, DE; obtained from Millipore-Sigma (Burlington, MA); catalog number 4942078001), type II collagenase (250 U/ $\mathrm{mL}$; ThermoFisher; catalog number 1710105), type IV collagenase $(250 \mathrm{U} / \mathrm{mL}$; ThermoFisher; catalog number 17104019), and $1 \times$ antibiotics/antimycotics, all in Hanks' balanced salt solution with with magnesium and calcium in a $37^{\circ} \mathrm{C}$ incubator that shakes back and forth 300 times a minute for 30 minutes. After this, the pieces were dislodged by pipetting up and down approximately 15 times with a 10$\mathrm{mL}$ serologic pipette to loosen the matrix and allow fibroblasts to freely move away from the tissue toward the plate during incubation.

Before digestion, the surface of 6-well plates was precoated with $2 \mathrm{~mL}$ of a solution containing rat-derived type I collagen solution (ThermoFisher; catalog number A1048301) diluted 1:20 in water from stock and placed them at $37^{\circ} \mathrm{C}$ for 1 hour to allow complete surface coverage. After digesting and mincing the tissue, the collagen solution was removed from the plates by aspiration, the dislodged tissue fragments were placed over the surface of the plates, and covered with approximately $300 \mu \mathrm{L}$ of fibroblast culture media, consisting of Dulbecco's modified Eagle's medium supplemented with $10 \%$ cosmic calf serum (Hyclone; GE Healthcare, Marlborough, MA), $1 \times$ nonessential amino acids plus L-glutamine (Gibco, Waltham, MA; catalog numbers 32561 to 037 ), and $1 \times$ antibiotic/antimycotic solution (Gibco, ThermoFisher). The medium was replaced every 4 days with new medium, adding just enough to cover the tissue fragments, allowing the outgrowth and expansion of the fibroblasts without hampering oxygen diffusion. Confluency with fibroblasts was achieved approximately 2 weeks after starting the explants. At this point, the cells were gently washed with Dulbecco's modified PBS (DPBS) plus $0.25 \mathrm{mmol} / \mathrm{L}$ EDTA, treated for 3 minutes with $0.25 \%$ trypsin (Gibco, ThermoFisher; catalog number 25200056), 
Table 1 List of Primers for RT-qPCR Used in This Study

\begin{tabular}{|c|c|c|}
\hline Gene & Forward primer & Reverse primer \\
\hline HPRT & 5'-CCTGGCGTCGTGATTAGTGAT-3' & $3^{\prime}$-AGACGTTCAGTCCTGTCCATAA-5' \\
\hline TGFB1 & $5^{\prime}-$ GGCCAGATCCTGTCCAAGC-3' & $3^{\prime}$-GTGGGTTTCCACCATTAGCAC-5' \\
\hline TGFB3 & 5'-АCTTGCACСАССТTGGACTTC-3' & $3^{\prime}$-GGTCATCACCGTTGGCTCA-5' \\
\hline CCN2 & $5^{\prime}$-ACCGACTGGAAGACACGTTTG-3' & $3^{\prime}-$ CCAGGTCAGCTTCGCAAGG $-5^{\prime}$ \\
\hline MMP1 & 5'-CTCTGGAGTAATGTCACACCTCT-3' & 3'-TGTTGGTCCACСTTTCATCTTC-5' \\
\hline MMPg & $5^{\prime}$-GGGACGCAGACATCGTCATC-3' & $3^{\prime}-$ TCGTCATCGTCGAAATGGGC-5' \\
\hline MMP10 & 5'-TCAGTCTCTCTACGGACCTCC-3' & $3^{\prime}-$ CAGTGGGATCTTCGCCAAAAATA-5' \\
\hline COL1A1 & 5'-ATCAACCGGAGGAATTTCCGT-3' & $3^{\prime}-\mathrm{CACCAGGACGACCAGGTTTTC-5^{ \prime }}$ \\
\hline COL1A2 & $5^{\prime}$-GGCCCTCAAGGTTTCCAAGG-3' & $3^{\prime}-\mathrm{CACCCTGTGGTCCAACAACTC-5^{ \prime }}$ \\
\hline COL7A1 & 5'-GGCTGCAАTTCTCCATGTGG-3' & $3^{\prime}$-CTGTGAGGCAACTCGCTTCA-5' \\
\hline
\end{tabular}

$\mathrm{RT}-\mathrm{qPCR}$, real time quantitative polymerase chain reaction.

and collected in complete media to neutralize the trypsin; we split them in newly coated plates in a 1:3 ratio.

\section{Phenotypic Characterization}

Fibroblasts were incubated in coverglass Nunc Lab-Tek II chamber slide systems (ThermoFisher, Waltham, MA) precoated with type I collagen as before at a density of $1 \times 10^{4}$ cells per $\mathrm{cm}^{2}$ in fibroblast media (see recipe above). Approximately 48 hours after initial seeding, the cells reached approximately $80 \%$ confluency, at which point they were used for staining. For this, the medium was removed, and the cells were washed once with DPBS solution and incubated in $4 \%$ paraformaldehyde in PBS (Santa Cruz Biotechnology, Dallas, TX; catalog number 3052589 to 4) for 10 minutes. After two washes in DPBS, the cells were incubated for 15 minutes in permeabilization buffer consisting of $0.25 \%$ Triton X-100 in PBS. After two washing steps, the cells were incubated for 1 hour at room temperature in blocking buffer, consisting of $10 \%(\mathrm{v} / \mathrm{v})$ normal goat serum, $1 \%(\mathrm{w} / \mathrm{v})$ bovine serum albumin, and $0.3 \mathrm{~mol} / \mathrm{L}$ glycine. Then, the buffer was removed, and new blocking buffer containing the prediluted unconjugated primary antibody was added. The cells were incubated in primary antibody overnight at $4{ }^{\circ} \mathrm{C}$. The following morning, the medium was removed, the cells were washed three times in PBS, and new blocking buffer containing prediluted secondary antibody was added. The secondary antibodies, all diluted 1:1000, are listed below. After an incubation period of 2 hours at room temperature, the secondary antibodies were removed, and the cells were washed five times in PBS before disassembling the chambers to then mount them in Vectashield medium containing DAPI (Vector Laboratories, Burlingame, CA; catalog number H1200). Imaging was performed with a Zeiss LSM 710 Axio Observer scanning laser confocal microscope (Zeiss Microscopy $\mathrm{GmbH}$, Jena, Germany) with a Plan-Apochromat $20 \times / 0.8$ objective running the Zen software version 2.3. Images were processed after acquisition using the FIJI software version 2.0.0-rc-68/1.52e (NIH, Bethesda, MD).

\section{Experiments with Primary Fibroblasts}

All experiments were performed in 10-cm tissue-culture dishes precoated with type I collagen, as described above. Primary fibroblasts between passages 3 and 8 were detached with $0.25 \%$ trypsin-EDTA (ThermoFisher Scientific, Waltham, MA; catalog number 25200056), washed in cold

Table 2 List of Primers Used for RT-qPCR in the Chromatin Immunoprecipitation Assays

\begin{tabular}{|c|c|c|c|}
\hline Gene & Set & Forward primer & Reverse primer \\
\hline hCCN2 & 1 & 5'-GCCTCTTCAGCTACCTACTT-3' & $3^{\prime}-\mathrm{CCTACACAAACAGGGACATTC}-5^{\prime}$ \\
\hline hCCN2 & 2 & 5'-GGTAGGCATCTTGAGGATTTC-3' & $3^{\prime}$-GCACCACTCCTGATTCATATC' - 5' \\
\hline SMAD2 in hCCN2 promoter & 6 & 5'-TGCGAAGAGGATAGGGAAA-3' & $3^{\prime}$-CCAATGAGCTGAATGGAGTC-5' \\
\hline SMAD2 in hCCN2 promoter & 8 & 5'-TTCTGTGAGCTGGAGTGT-3' & 3'-GGGAAGAGTTGTTGTGTGAG-5' \\
\hline hMMPg & 2 & $5^{\prime}$-GAGGAAGCTGAGTCAAAGAAG-3' & 3'-GAGCTTGTGGGAACTGTATG-5' \\
\hline hHPRT & 3 & 5'-ACTCCTGACCTTGAGTGAT-3' & $3^{\prime}$-GTTGAGACCTAGAGTCCTAGAG-5' \\
\hline$h G A P D H$ & 1 & $5^{\prime}$-CAGGCTGGATGGAATGAAA - 3' & $3^{\prime}$-GAGGTTTCTGCACGGAAG-5' \\
\hline
\end{tabular}

$\mathrm{RT}-\mathrm{qPCR}$, real time quantitative polymerase chain reaction. 
DPBS, resuspended in complete medium at $1.5 \times 10^{4} \mathrm{fi}-$ broblasts $/ \mathrm{mL}$, and seeded at an initial density of $1.5 \times 10^{5}$ fibroblasts per $\mathrm{cm}^{2}$ for 24 hours. Then, the medium was removed and replaced with fresh medium containing the following modulators: recombinant human transforming growth factor beta-1 (PeproTech, Rocky Hill, NJ; produced in HEK293 cells; catalog number 100 to 21), recombinant human cellular communication network factor 2 (PeproTech; Escherichia coli derived; catalog number 120 to 19), and triamcinolone acetonide suspension (Kenalog-40; 40 $\mathrm{mg} / \mathrm{mL}$; Bristol-Myers Squibb, New York, NY), the SMAD3 inhibitor, SISI3 (10 $\mu \mathrm{mol} / \mathrm{L}$; Tocris, Bristol, UK; catalog number 5291), or a combination of those, as specified in the text.

\section{Histologic Studies}

\section{Bright-Field Microscopy}

Formalin-fixed, paraffin-embedded blocks and OCTembedded frozen blocks were cut into sections $(5 \mu \mathrm{m}$ thick), placed into (+)-charged super-frost microscope slides, and stained with routine hematoxylin and eosin and Masson trichrome staining methods. The formalin-fixed, paraffin-embedded blocks were obtained from the Mass Ear and Eye Pathology Department (Boston, MA). For the morphometric and structural analyses, we studied the subglottises of 14 patients with iSGS from the pathology archive. The subglottises of patients who underwent total laryngectomy due to laryngeal cancer $(n=10)$ were used
A
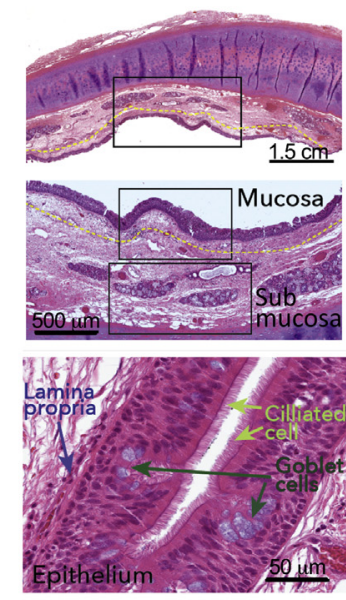

B

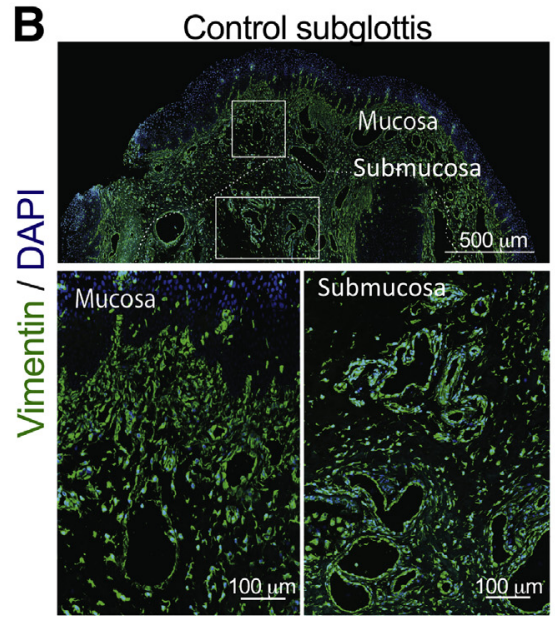

Control subglottis (H\&E)
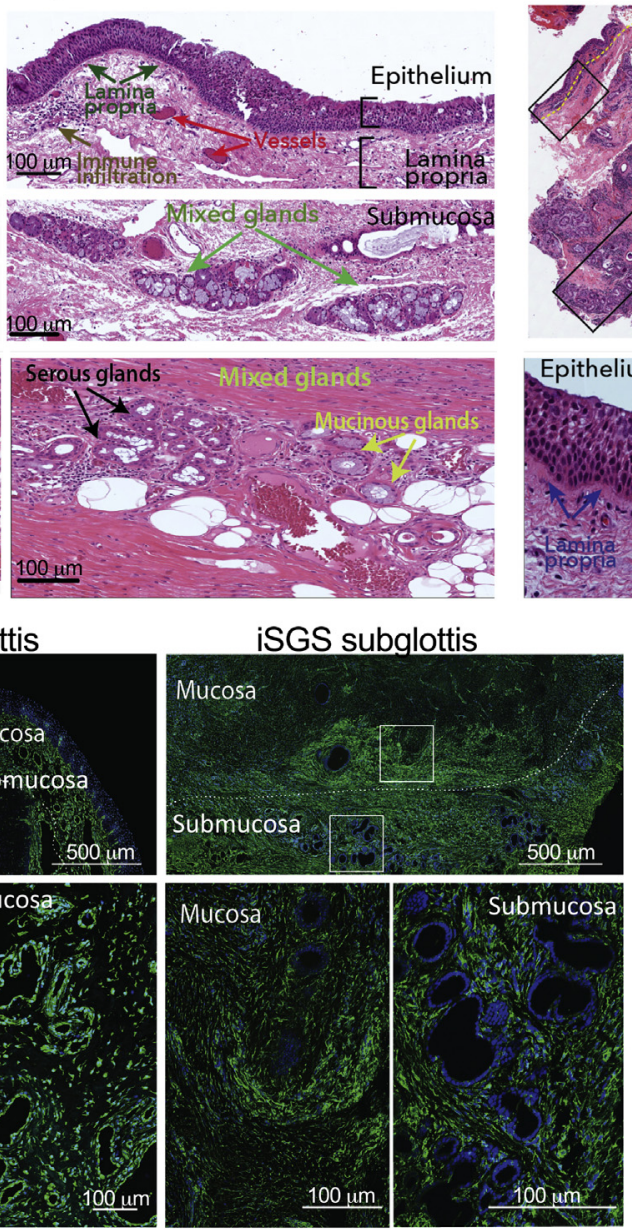

iSGS subglottis (H\&E)
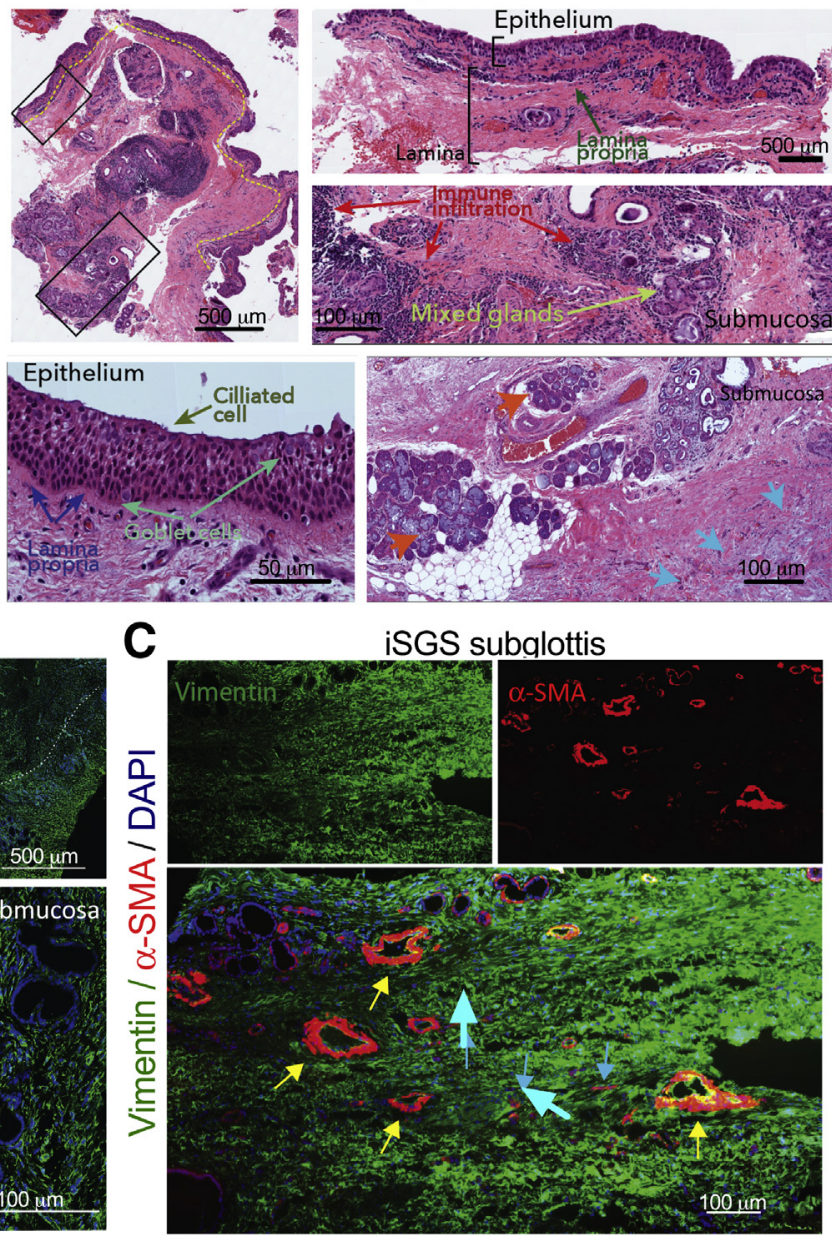

Figure 1 Characterization of the subglottic stromal composition in idiopathic subglottic stenosis (iSGS). A: Representative hematoxylin and eosin (H\&E)-stained micrographs of formalin-fixed, paraffin-embedded sections from control/normal subglottises from a patient who underwent total laryngectomy, without prior radiotherapy, due to laryngeal cancer that did not extend to the subglottis (six leftmost panels) or from a patient with iSGS (five rightmost panels). The yellow dashed lines delineate the virtual boundaries between mucosa and submucosa layers. Boxed areas delineate regions of interest within the mucosa or submucosa, presented at a higher magnification in the micrographs below. Colored arrows point to the structures labeled with the same color. B: Representative confocal images of a control subglottis (left panels) and the subglottis of a patient with iSGS (right panels), costained for vimentin (green) and DAPI (blue) for nuclear visualization. White dashed line delineates the separation between mucosa and submucosa. The white boxed areas in the top micrographs delineate regions of mucosa and submucosa, magnified for better visualization in the micrographs below. C: Representative confocal images of the subglottis of the patient with iSGS, costained for vimentin (green), $\alpha$-smooth muscle actin ( $\alpha$-SMA; red), and DAPI (blue). Blue arrows point to few scattered myofibroblasts. Yellow arrows point to perivascular $\alpha$-SMA cells. Scale bars: $1.5 \mathrm{~cm} \mathrm{(A);50} \mu \mathrm{m}(\mathbf{A}) ; 100 \mu \mathrm{m}(\mathbf{A}$ and B, bottom panels); $500 \mu \mathrm{m}$ (A and B, top panels). 

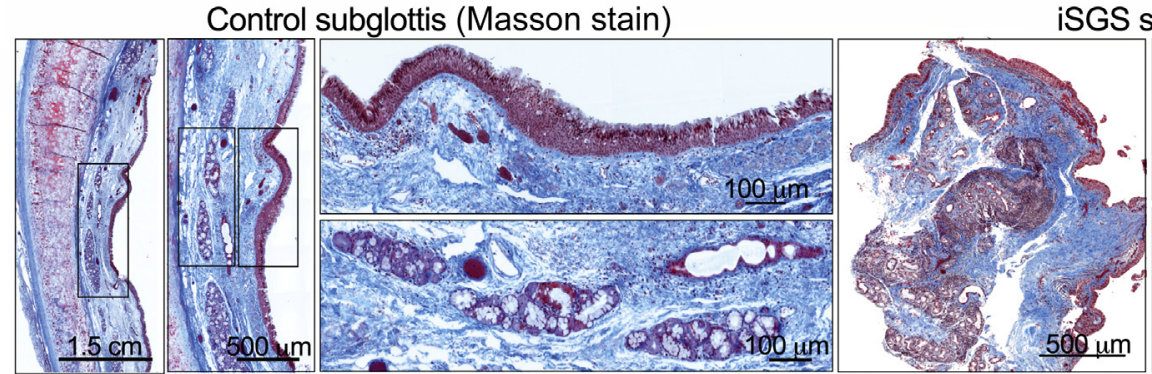

iSGS subglottis (Masson stain)
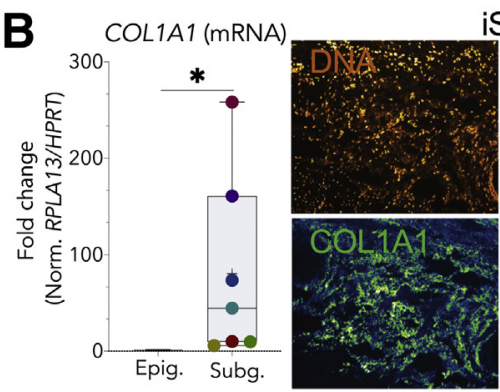

iSGS subglottis
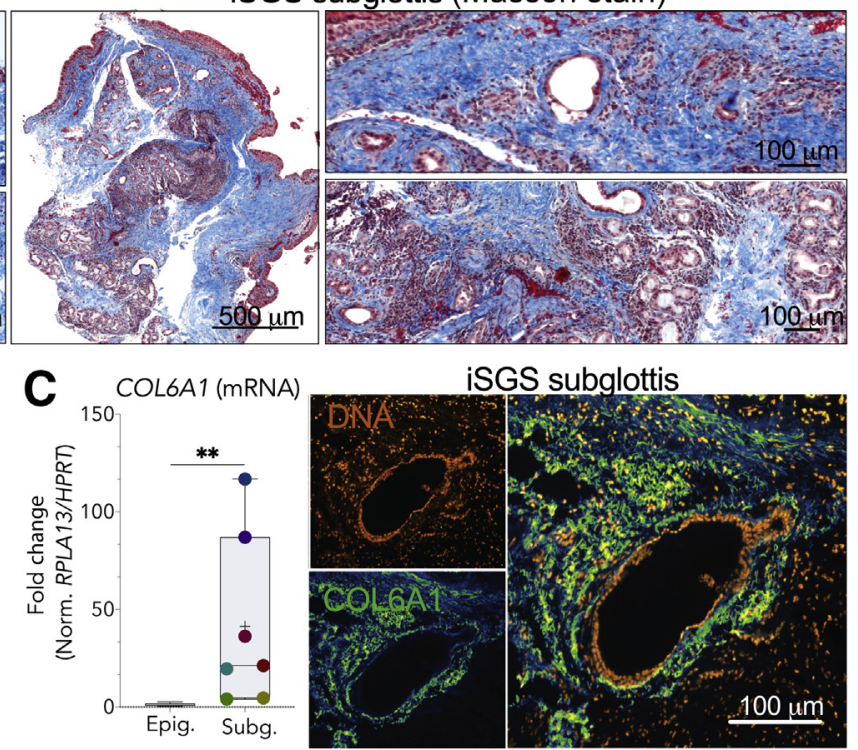

D
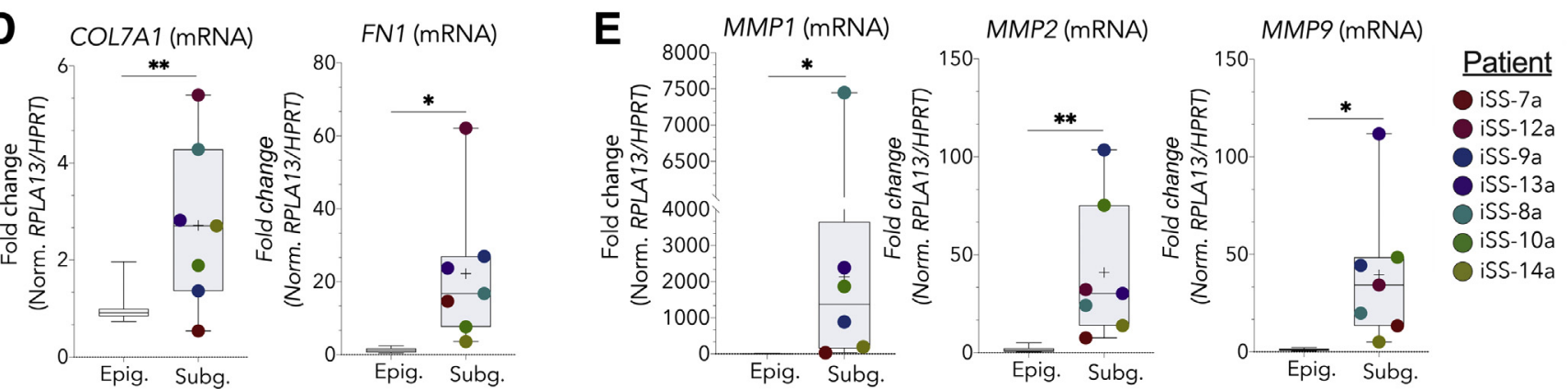

Figure 2 Extracellular matrix (ECM) composition in the subglottis of patients with idiopathic subglottic stenosis (iSGS). A: Representative Masson trichrome-stained micrographs of formalin-fixed, paraffin-embedded sections from control/normal subglottis from a patient who underwent total laryngectomy, without prior radiotherapy, due to laryngeal cancer that did not extend to the subglottis (left panels) or from a patient with iSGS (right panels). Boxed areas delineate the areas shown in subsequent magnifications. B-E: Gene expression analysis by RT-qPCR of genes involved in the synthesis and remodeling of the ECM. Each colored dot represents an individual patient in whom the levels of mRNA in his/her subglottis (Subg.) were normalized (Norm.) and compared with that of his/her own normal epiglottic (control) tissue (Epig.). B: Collagen 1 subunit A isoform 1 (COL1A1) mRNA (two-tailed, paired parametric $t$-test). COL1A1 protein expression and distribution, visualized by confocal microscopy, is shown on the right (COL1A1, fire green; DAPI, orange). C: Collagen 6 subunit A isoform 1 (COL6A1) mRNA (two-tailed, paired parametric $t$-test). COL6A1 protein expression and distribution, analyzed by confocal microscopy, is shown on the right (COL6A1, fire green; DAPI, orange). D: Collagen 7 subunit A isoform 1 (COL7A1; two-tailed, paired parametric $t$-test); fibronectin (FN1; two-tailed, ratio paired parametric $t$-test). E: mRNA expression of the matrix remodeling genes: metalloprotease 1 (MMP1; Wilcoxon matchedpairs signed rank test), metalloprotease 2 (MMP2; Wilcoxon matched-pairs signed rank test), and metalloprotease 9 (MMP9; two-tailed, paired parametric $t$ test). Data are expressed as means $\pm \mathrm{SD}(\mathbf{B}-\mathbf{E}) . n=7$ (B, COL1A1, C, COL6A1, D, COL7A1 and FN1, and E, MMP2 and MMP9); $n=6(\mathbf{E}, M M P 1) .{ }^{*} P<0.05$, $* * P<0.01$. Scale bars: $1.5 \mathrm{~cm}(\mathbf{A}) ; 100 \mu \mathrm{m}(\mathbf{A}-\mathbf{C}) ; 500 \mu \mathrm{m}(\mathbf{A})$.

as morphologic control. More important, none of the patients used as controls had cancer involving the subglottic mucosa or the cricoid cartilage. In addition, we used biopsies of a patient with tracheitis and the subglottis of a patient with granulomatosis with polyangiitis for comparison. Bright-field images were acquired using a motorized Inverted Axio Observer Z1/7 microscope (Carl Zeiss GmbH, Jena, Germany) using an AxioCamMRc3 color camera and the Zen 2.3 blue edition version 2.3 69.1000 (Zeiss, Jena, Germany) for image acquisition. Sections were visualized using an LD Plan-Neofluar $20 \times 1$ 0.4 Korr Ph2 M27 and a Plan-apochromat $40 \times / 1.3$ oil differential interference contrast (UV) Vis-IR M27 objectives (Zeiss Microscopy, Jena, Germany). Every image was acquired using the tile functionality from the software and processed after acquisition with the FIJI software version 2.0.0-rc-68/1.52e.

Immunofluorescence Labeling in Frozen Sections

Frozen subglottic samples were embedded in OCT and sectioned into slices $(6 \mu \mathrm{m}$ thick) using a cryostat. The slides were immediately immersed in $4 \%(\mathrm{v} / \mathrm{v})$ paraformaldehyde for 10 minutes, washed in DPBS, and permeabilized in $0.25 \%$ Triton $\mathrm{X}-100$ in tris-buffered saline. After washing in tris-buffered saline, sections were blocked for 30 minutes with blocking buffer [10\% 


\section{A TGFB1 (mRNA) TGF- $\beta 1$ (protein)}
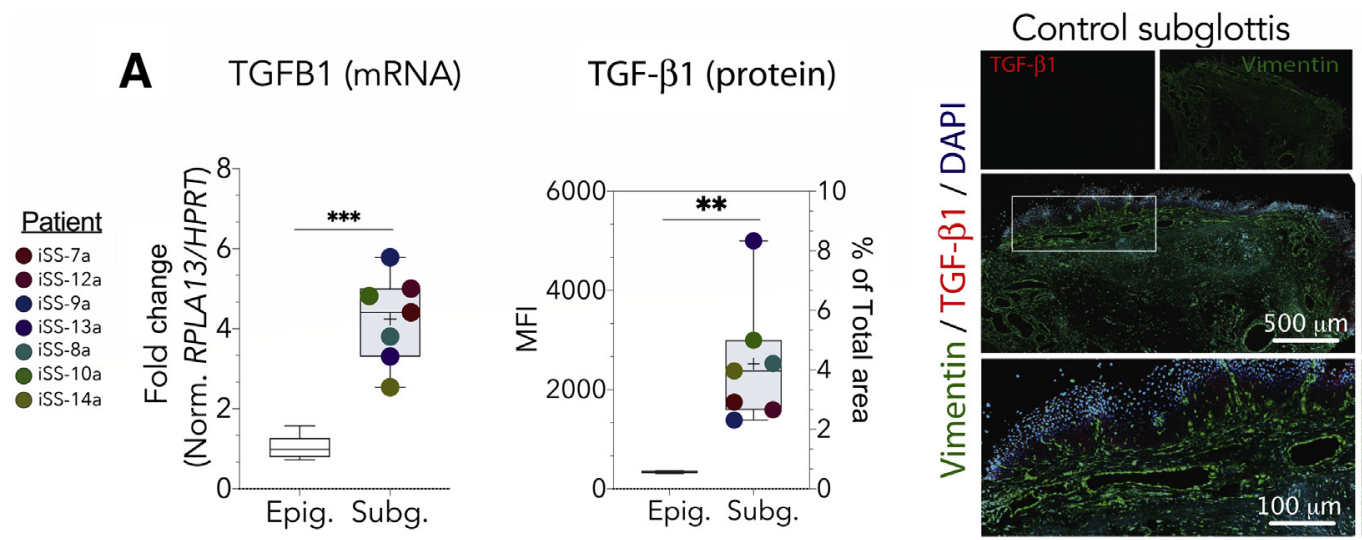

iSGS subglottis

B

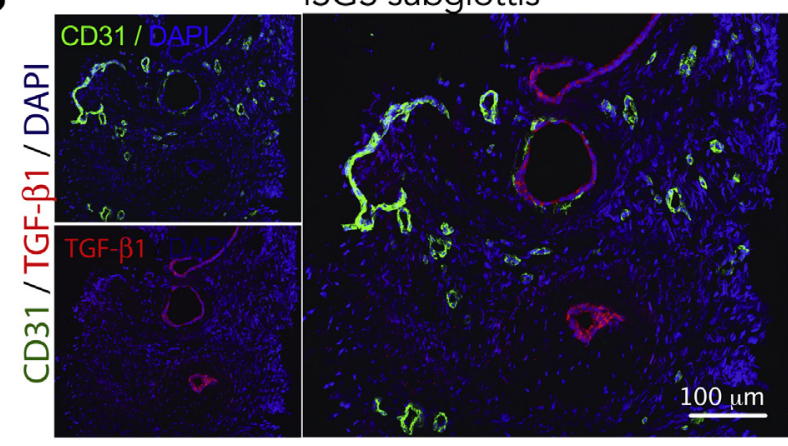

D
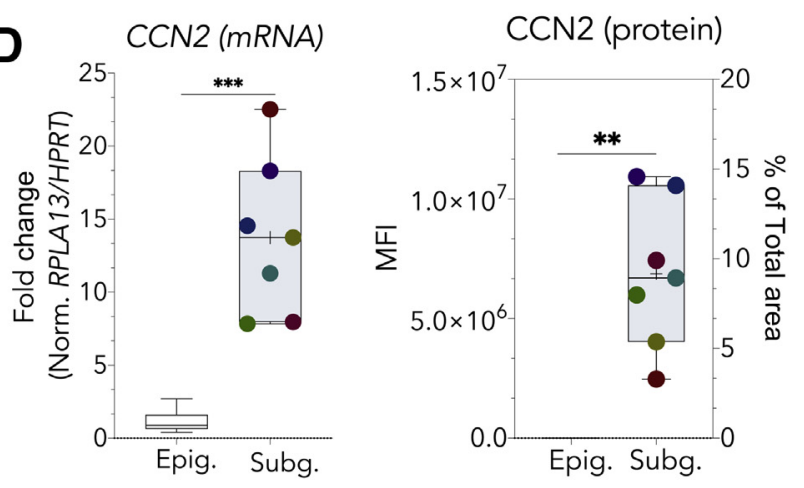

iSGS subglottis

C

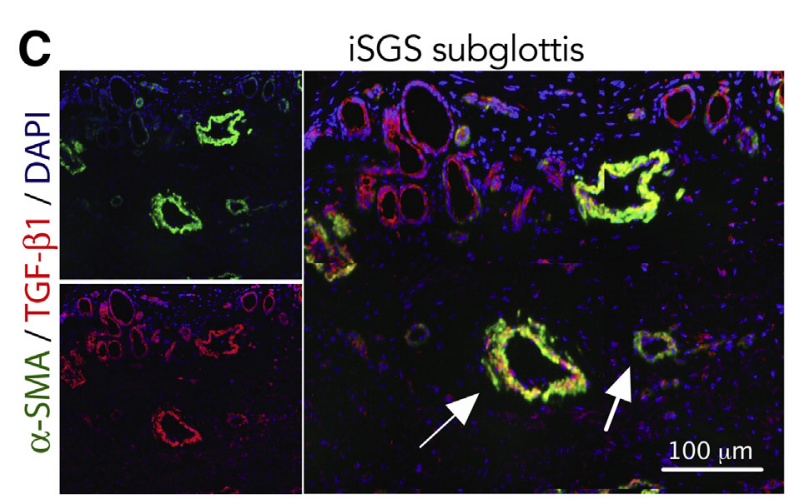

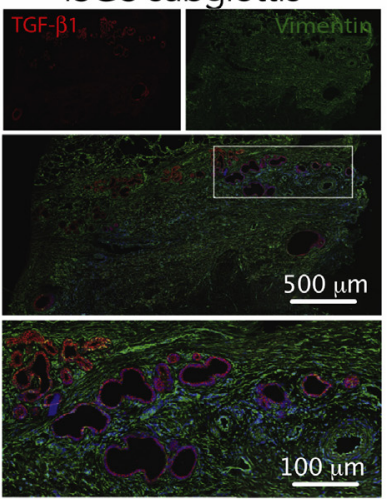

$100 \mathrm{um}$

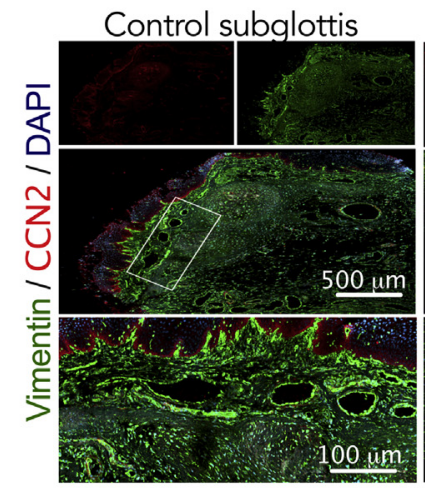

iSGS subglottis

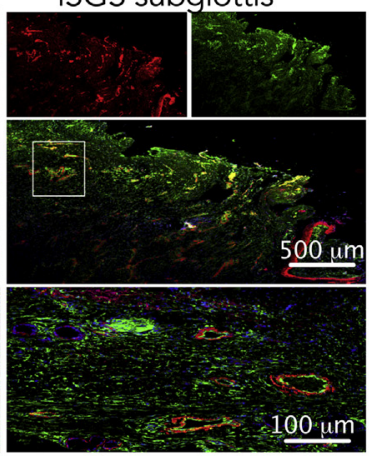

E
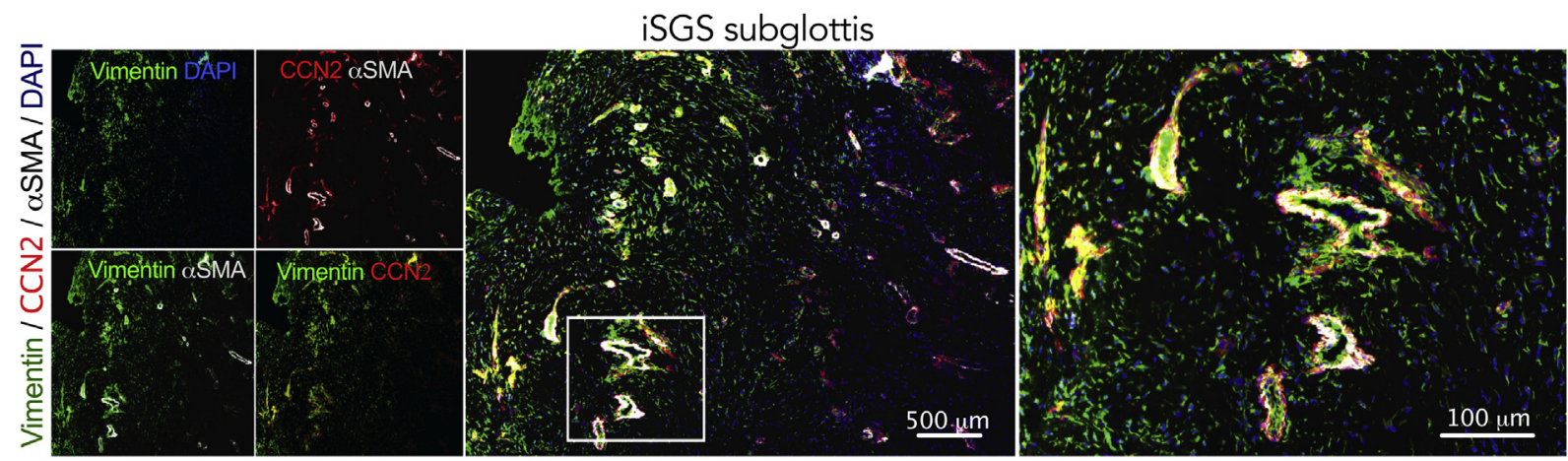
$(\mathrm{v} / \mathrm{v})$ normal goat serum, $1 \%(\mathrm{w} / \mathrm{v})$ bovine serum albu$\mathrm{min}$, and $0.3 \mathrm{~mol} / \mathrm{L}$ glycine] and incubated overnight with primary antibody. After washing, sections were incubated with a secondary goat anti-rabbit Alexa 568-conjugated antibody (also diluted in blocking buffer) for 2 hours at room temperature. After incubation, tissue sections were washed and mounted in Vectashield mounting medium containing DAPI (Vector Laboratories, Inc., Burlingame, CA). Imaging was performed with an LSM 710 Axio Observed scanning laser confocal microscope with a Plan-Apochromat $20 \times / 0.8$ objective using the Zen software version 2.3. Images were processed after acquisition using the FIJI software version 2.0.0-rc-68/1.52e, and manipulated only to enhance contrast and light exposure in a linear manner simultaneously in all channels, using Adobe Photoshop 11.0.2 (Adobe Systems, San Jose, CA).

\section{Antibodies}

The following primary antibodies at the following dilutions were used in this study: from Santa Cruz Biotechnology: mouse monoclonal (3C4) anti-collagen VI alpha (catalog number sc-47712; diluted 1:150); from Abcam (Cambridge, MA): chicken polyclonal anti-vimentin (catalog number ab39376; diluted 1:200), mouse monoclonal (RV202) antivimentin (catalog number 8978; diluted 1:200), rabbit monoclonal (EPR3776) anti-vimentin (catalog number ab92547; diluted 1:300), rabbit polyclonal anti- $\alpha$-smooth muscle actin ( $\alpha$-SMA; catalog number ab5694; diluted 1:200), mouse monoclonal (1A4) anti- $\alpha$-SMA (catalog number ab7817; diluted 1:200), rabbit polyclonal anti-TGF- $\beta 1$ (catalog number ab92486; diluted 1:400), and rabbit polyclonal anti-connective tissue growth factor (catalog number ab6992; diluted 1:200). The following fluorochrome-conjugated secondary antibodies were used (all from Thermo Fisher Scientific, and used at a 1:1000 dilution, unless specified otherwise): Alexa 488 goat antichicken IgY (catalog number A32931; diluted 1:1200),
Alexa 488 goat anti-mouse IgG (catalog number A32723), Alexa 568 goat anti-mouse IgG (catalog number A-11004; diluted 1:1500), Alexa 647 goat anti-mouse IgG (catalog number A32728; diluted 1:800), Alexa 488 goat anti-rabbit IgG (catalog number A32731), Alexa 568 goat anti-rabbit (catalog number A11011; diluted 1:1200), and Alexa 488 goat anti-hamster IgG (catalog number A-21110).

\section{Gene Expression}

Gene expression was measured as previously described. ${ }^{29}$ The geometric mean of the housekeeping genes HPRT and $18 \mathrm{~S}$ was used to normalize variation in gene expression. Data are expressed as fold change relative to the control group, either the epiglottis or the untreated subglottis. The primers used herein are listed in Table 1.

\section{Chromatin Immunoprecipitation}

Acetylation levels in histones $\mathrm{H} 3$ and $\mathrm{H} 4$ (H3KA, H4KAc) surrounding the $M M P 9$ and $C C N 2$ promoters, and the binding capacity of SMAD2/3 to the $C C N 2$ gene promoter segment, were evaluated using chromatin immunoprecipitation assays. Promoters were defined as DNA segments $-500 \mathrm{bp}$ from the first exon, and the primers listed in Table 2 were designed to fall near transcriptional sites like TATA sequences. The primers to evaluate SMAD2/3 binding to the $C C N 2$ promoter were designed to flank the CAGACGGAGGAA SMAD binding region located upstream of the first exon of $C C N 2$. The following antibodies were used in these experiments: rabbit monoclonal (D7G7) anti-SMAD2/3 (Cell Signaling, Danvers, MA; catalog number 8685), rabbit polyclonal acetylated H4 (Millipore, Burlington, MA; catalog number 06 to 866), polyclonal acetylated H3 (Millipore; catalog number 06 to 599), and rabbit IgG as control (Santa Cruz Biotechnology; catalog number SC2027). Fold enrichment was calculated as chromatin immunoprecipitation signals normalized to input

\footnotetext{
Figure 3 Transforming growth factor (TGF)- $\beta 1$ and cellular communication network factor 2 (CCN2) are up-regulated in the subglottis (Subg.) of idiopathic subglottic stenosis (iSGS) patients. A: TGF 1 mRNA (two-tailed, paired parametric $t$-test) and protein levels, analyzed using confocal microscopy (two-tailed, paired parametric $t$-test). A representative confocal microscopy image of the subglottis of a patient with iSGS labeled against vimentin (green) and TGF- $\beta 1$ (red), used for quantitation, is shown on the right. The uppermost micrographs correspond to single-channel micrographs showing TGF- $\beta 1$ (red) and vimentin (green) expression. The white boxed areas delineate regions of the subglottic stroma magnified for better visualization in the micrographs below. B: Representative confocal microscopy image of the subglottis of a patient with iSGS labeled against the endothelial marker, CD31 (green), and TGF- $\beta 1$ (red). C: Representative confocal microscopy image of the subglottis of a patient with iSGS labeled against $\alpha$-smooth muscle actin ( $\alpha$-SMA; green) and TGF- $\beta 1$ (red). Arrows point to perivascular $\alpha$-SMA cells (probably pericytes) co-expressing TGF- $\beta$. D: Cellular communication network factor 2 (CCN2) mRNA (two-tailed, paired parametric $t$-test) and protein levels in the subglottis of iSGS patients analyzed using confocal microscopy (two-tailed, paired parametric $t$-test). A representative confocal microscopy image of the subglottis of a patient with iSGS labeled against vimentin (green) and CCN2 (red), used for quantitation, is shown on the right. The uppermost micrographs in the panel correspond to single-channel micrographs showing CCN2 (red) and vimentin (green) expression. The white boxed areas delineate regions of the subglottic stroma magnified for better visualization in the micrographs below. E: Representative confocal microscopy image of the subglottis of a patient with iSGS labeled simultaneously for vimentin (white), $\alpha$-SMA (green), CCN2 (red), and DAPI (blue). In all micrographs, DAPI was used to counterstain the nuclei. The white boxed areas delineate a region of the subglottic magnified for better visualization in the micrograph on the right. Data are expressed as means \pm SD (A and $\mathbf{D}) . n=7$ (A and $\mathbf{D})$. ${ }^{* *} P<0.01,{ }^{* *} P<0.001$. Scale bars: $500 \mu \mathrm{m}(\mathbf{A}, \mathbf{D}$, and $\mathbf{E}$, white boxed areas); $100 \mu \mathrm{m}$ (A-E). Epig., epiglottis; Norm., normalized.
} 
DNA and to a housekeeping gene. Each experiment was performed in triplicate.

\section{Immunoblotting}

Immunoblot was performed as previously reported. ${ }^{29}$ The rabbit polyclonal anti-connective tissue growth factor (Abcam; catalog number ab6992; diluted 1:150) was used.

\section{Statistical Analysis}

Comparisons between two groups were performed using $t$-tests, as described in the figure legends. The choice of parametric versus nonparametric analyses was based on analysis for normal distribution based on the Shapiro-Wilk and Kolmogorov-Smirnov distribution test, considering an $\alpha>0.05$ as threshold for normality.

\section{Results}

\section{Characterization of Subglottal Stromal Composition in iSGS}

The morphologic and structural changes occurring in the subglottises as a result of iSGS were investigated. The subglottis from patients who underwent total laryngectomy for canceser but had no tumor invasion or history of radiotherapy were used as control. Two distinctive layers were evident in the subglottises of the patients used as control for normal morphology: an external mucosa facing the airway and an internal submucosal layer (Figure 1A). The control mucosal layer was composed of pseudostratified cylindric ciliated epithelium, intercalating with gobletmucous producing cells, a basal lamina, and a lamina propria that contained small stromal vessels and few regularly scattered fibroblasts with scant inflammatory cells near the basal membrane (Figure 1A). The control submucosa contained larger vessels, mixed serous/mucinous glands, and fibroblasts scattered throughout the stroma. In contrast, the subglottises of patients with iSGS exhibited a loss of the normal features described in our control samples. The clear demarcation between the mucosa and submucosa layers was lost because of extensive mucus stromal deposition, tissue swelling, and an extensive interstitial chronic fibroinflammatory infiltrative process.

The mucosa in the subglottises of patients with iSGS was hyperplastic, had fewer and degenerated goblet cells, presented a discontinuous loss in the basal lamina, and exhibited metaplastic changes in some areas based on the loss of the ciliated brush border (Figure 1A). The subglottic submucosa of patients with iSGS was hypervascular, was swollen with fluid and mucus deposition, presented important nodular inflammatory infiltrations with cells of lymphoid appearance, and exhibited remarkable glandular changes that included mucus epithelial metaplasia, glandular sclerosis, and a periglandular inflammatory infiltration that was associated with glandular destruction (Figure 1A).

Fibroblasts were a predominant cell population in the subglottises of patients with iSGS (Figure 1B). Unlike control subglottises, the subglottises of patients with iSGS presented a diffused fibroblastic infiltrative response, especially near the glands, where they tended to organize in sheets or cell layers (Figure 1B). Strikingly, the stromal fibroblasts in the subglottises of iSGS patients shared the same vimentin-positive $\alpha$-SMA ${ }^{-}$phenotype observed in our control subglottic samples, indicating a lack of myofibroblast differentiation and/or no involvement of these cells in iSGS (Figure 1, B and C). $\alpha$-SMA expression was mostly confined to cells surrounding vessel-like structures, possibly pericytes (Figure 1C).

In comparison to control subglottis, iSGS exhibited a disorganized pattern of ECM deposition in the lamina propria and the submucosa (Figure 2A). iSGS subglottises also had significantly higher levels of collagen 1 (COL1A1), collagen 6 (COL6A1), collagen 7 (COL7AI), and fibronectin (FNI) mRNA when compared with their own matched epiglottis (Figure 2, B-D). The expression and distribution of types 1 and 6 collagens was corroborated by confocal microscopy (Figure 2, B and D), where scattered distribution of these proteins were observed throughout the stroma and surrounding vascular and glandular structures. The subglottises of patients with iSGS also exhibited important changes in ECM remodeling genes, which included a significant induction of the metalloproteases $M M P 1, M M P 2$, and $M M P 9$ (Figure 2E).

\section{Increased Expression of TGF- $\beta 1$ and CCN2 in the Subglottises of iSGS Patients}

The expression of mediators commonly dysregulated in idiopathic fibrosis, emphasizing TGF- $\beta 1$ was measured. ${ }^{10}$ Compared with control epiglottis, TGF $1 \mathrm{mRNA}$ and protein levels were significantly up-regulated in the subglottises of iSGS patients (Figure 3A). Remarkably, TGF- $\beta 1$ expression was seldom detectable in subglottic fibroblasts and, instead, its expression was confined to the submucosal mixed glands and to some stromal vascular structures located throughout the subglottises of iSGS patients (Figure 3B). CD31/TGF- $\beta 1$ colabeling was performed to interrogate a potential endothelial source of this mediator in those vascular-like structures. Indeed, the vascular-like structures were lined with $\mathrm{CD} 31^{+}$cells, confirming their vascular nature (Figure 3B). However, TGF- $\beta 1$ was not expressed in any $\mathrm{CD} 31^{+}$endothelial cells, indicating that the blood vessels are not the source for this cytokine (Figure 3C). Instead, the immunoreactivity for TGF- $\beta 1$ was localized in $\alpha-\mathrm{SMA}^{+} / \mathrm{CD} 31^{-}$perivascular cells, likely pericytes, located throughout the subglottises of iSGS patients (Figure 3C). 
A

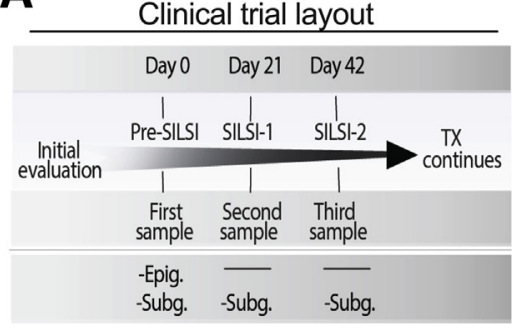

B

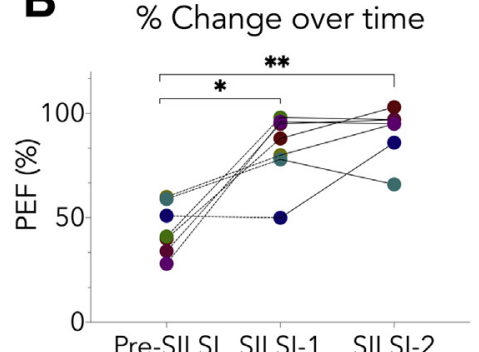

Pre-SILSI SILSI-1 SILSI-2
C

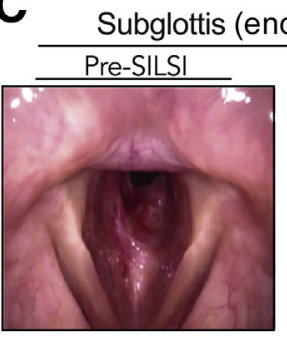

TNFA (mRNA)

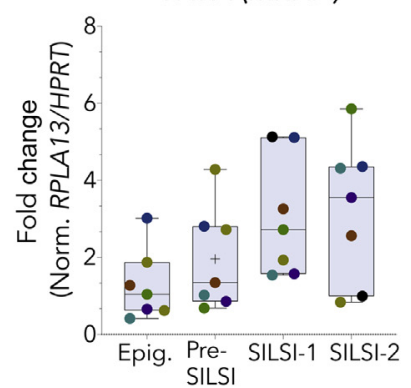

IL18 (mRNA)

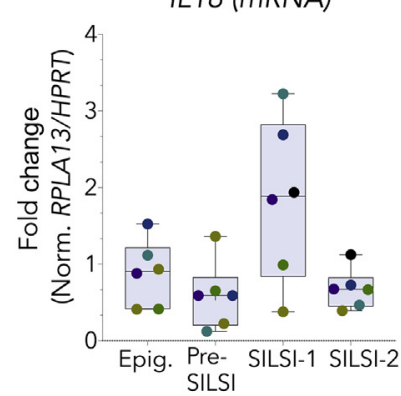

Figure 4 Two consecutives serial intralesional steroid injection (SILSI) treatments (TX) improve clinical outcomes in patients with idiopathic subglottic stenosis (iSGS). A: Schematic depiction of the prospective clinical trial, showing how the course of tissue harvesting and steroid injections was performed. B: Changes in peak expiratory force percentage (PEF\%) over time, before and during the first two rounds of SILSI treatment [repeated-measures analysis of variance (ANOVA) with Geisser-Greenhouse correction and Dunnett test comparing pre-SILSI versus SILSI-1 and pre-SILSI versus SILSI-2]. C: Representative endoscopic images of the subglottis (Subg.) in a patient before (pre-SILSI; left panel) and 3 weeks after the endoscopic resection of scar and injection of triamcinolone (SILSI-1; right panel). D: mRNA gene expression analysis of profibrotic cytokines expressed in subglottic biopsies taken from patients with iSGS before, after one round of treatment, and after a second round of treatment (SILSI-2). Patient-matched epiglottic (Epig.) samples were used to normalize and to set baseline gene expression levels. Each colored dot represents an individual patient, matched to itself across the different groups in the study. The cytokines measured were as follows: IL1B (Friedman paired nonparametric one-way ANOVA with Dunn multiple-comparison post-test), IL16 (paired one-way ANOVA with Tukey post-test), TNFA (paired one-way ANOVA with Tukey post-test), and IL18 (paired one-way ANOVA with Tukey post-test). Data are expressed as means \pm SD (D). $n=7$ (B and D, IL1B and TNFA); $n=6$ (D, IL16 and IL18). ${ }^{*} P<0.05,{ }^{* *} P<0.01$, and ${ }^{* * *} P<0.001$.

TGF- $\beta 1$ stimulates the production of additional profibrotic mediators that serve to amplify the profibrotic effects of this cytokine. One such factor is CCN2, which plays a key role in promoting fibroblast migration and proliferation, and whose levels of mRNA and protein expression were significantly elevated in the subglottis of iSGS patients (Figure 3D). In reminiscence to TGF- $\beta 1,{ }^{23,27} \mathrm{CCN} 2$ also exhibited a particular pattern of tissue expression, mainly located in some fibroblasts as well as $\alpha$-SMA ${ }^{+}$cells, that were likely perivascular pericytes (Figure 3D). To conclusively confirm their involvement, a four-color confocal microcopy analysis was performed where the levels and patterns of CD31, $\alpha$-SMA, CCN2, and DAPI were evaluated simultaneously (Figure 3E). Indeed, the expression of $\mathrm{CCN} 2$ was confined to DAPI, $\alpha-\mathrm{SMA}^{+}, \mathrm{CCN} 2^{+}$, and vimentin-negative/vimentin-positive cells, whose pattern of markers is highly concordant to that of perivascular pericytes (Figure 3E).

Table 3 Epidemiologic and Clinical Data of the Patients Recruited to Receive Two Sequential Rounds of SILSI in the Subglottis to Treat Symptomatic iSGS

\begin{tabular}{llllll}
\hline Subject no. & Age, years & Baseline PEF\% & SILSI-1 PEF\% & SILSI-2 PEF\% & Improvement in PEF\% \\
\hline 1 & 37 & 40 & 88 & 103 & 63 \\
2 & 62 & 60 & 80 & 95 & 35 \\
3 & 46 & 41 & 98 & 98 & 57 \\
4 & 70 & 59 & 95 & 66 & 7 \\
5 & 36 & 96 & 97 & 63 \\
6 & 33 & 28 & 50 & 95 & 67 \\
7 & 81 & 51 & 86 & 35 \\
\hline
\end{tabular}

PEF\% values, obtained using forced spirometry, were used to assess clinical improvement of the airway narrowing in our patients. iSGS, idiopathic subglottic stenosis; PEF\%, peak expiratory flow percentage; SILSI, serial intralesional steroid injection. 

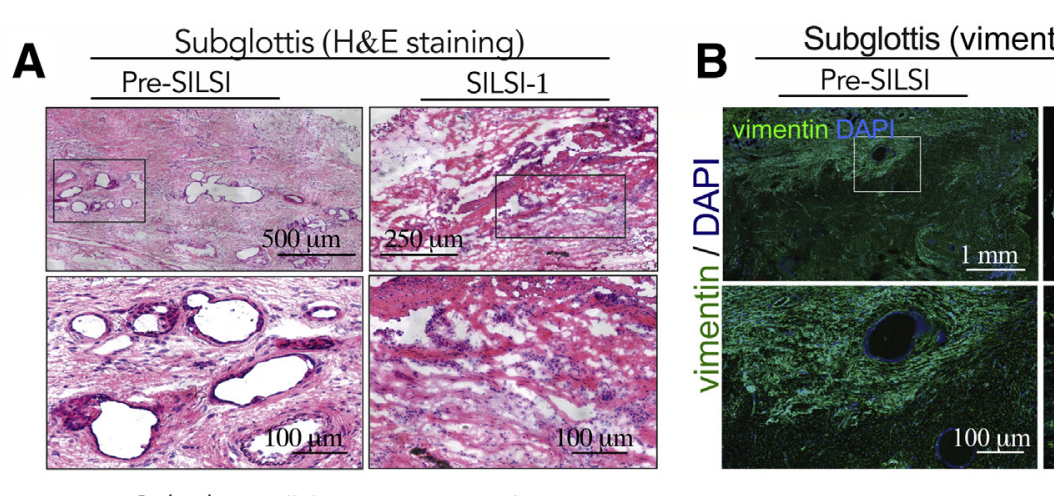

vimentin + fibroblasts
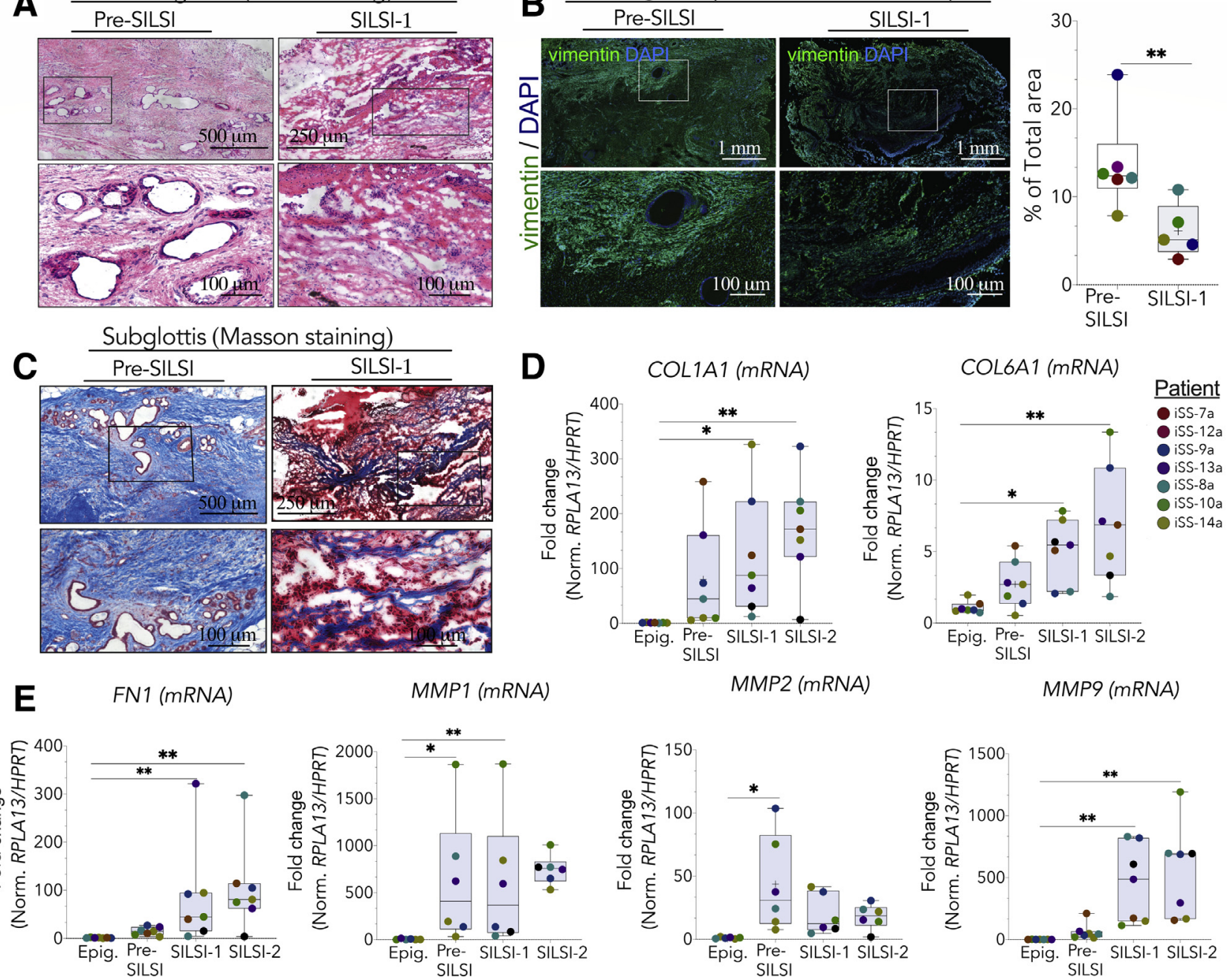

Figure 5 Serial intralesional steroid injection SILSI) minimizes the fibroblastic response and stimulates extracellular matrix remodeling. A: Representative hematoxylin and eosin (H\&E)-stained micrographs of the subglottis of a patient pre-SILSI (left panels) and after a round of triamcinolone injection (SILSI-1; right panels). Boxed areas delineate the areas shown in the magnifications below. B: Representative confocal images of the subglottis of an idiopathic subglottic stenosis (iSGS) patient stained for vimentin (green) and DAPI (blue), before (pre-SILSI; left panels) and 3 weeks after one steroid injection (SILSI1 ; right panels). Quantification of the total area containing vimentin-positive fibroblasts is shown (two-tailed unpaired $t$-test). Boxed areas in upper micrographs delineate areas magnified for better visualization in the images below. C: Representative Masson trichrome staining of the subglottis of a pre-SILSI (left panels) and an SILSI-1 (right panels) patient. Boxed areas delineate the areas shown in the magnifications below. D and E: $m$ RNA gene expression analysis of subglottic biopsies taken from patients with iSGS pre-SILSI, SILSI-1, and SILSI-2 (two rounds of steroid injections). A patient-matched epiglottis (Epig.) sample from each patient was used to establish baseline gene expression. D: Collagen type 1A1 [COL1A1; Friedman paired nonparametric one-way analysis of variance (ANOVA) with Dunn multiple-comparison post-test]. Collagen type 6 mRNA expression (COL6A1; paired one-way ANOVA with Tukey post-test). E: Fibronectin (FN1; Friedman paired nonparametric one-way ANOVA with Dunn multiple-comparison post-test); metalloprotease type I (MMP1; Friedman paired nonparametric one-way ANOVA with Dunn post-test); MMP2 (Friedman paired nonparametric one-way ANOVA with Dunn multiple-comparison post-test); and MMP9 (paired one-way ANOVA with Tukey post-test). Data are expressed as means \pm SD (B, D, and E). $n=6$ (B, pre-SILSI, and E, MMP2); $n$ $=5$ (B, SILSI-1); $n=7$ (D and E, FN1, MMP1, and MMP9). ${ }^{*} P<0.05,{ }^{*} P<0.01$. Scale bars: $500 \mu \mathrm{m}$ (A and $\mathbf{C}$, top left panel); $250 \mu \mathrm{m}(\mathbf{A}$ and $\mathbf{C}$, top right panel); $100 \mu \mathrm{m}$ (A-C, bottom panels); $1 \mathrm{~mm}$ (B, boxed areas). Norm., normalized.

Two Consecutive Rounds of Intralesional Steroidal Injections Improve the Clinical Outcome of Patients with iSGS

The effect of SILSI was tested to improve the clinical outcome in seven consecutive iSGS patients who had never been treated for their stenosis before. The diagram depicted in Figure 4A describes the design of the study. ${ }^{30}$ All patients were symptomatic at baseline, with exertional dyspnea due to the subglottic stenosis, which led to forced spirometry values ranging well below normal (mean starting PEF $\%=45 \%$ when normal is PEF\% $>80 \%$ ). After an initial endoscopic removal of scar plus steroid injection and two subsequent in-office subglottic steroid injections, the airway diameter of all patients increased, translating into a statistically significant improvement in forced spirometry 

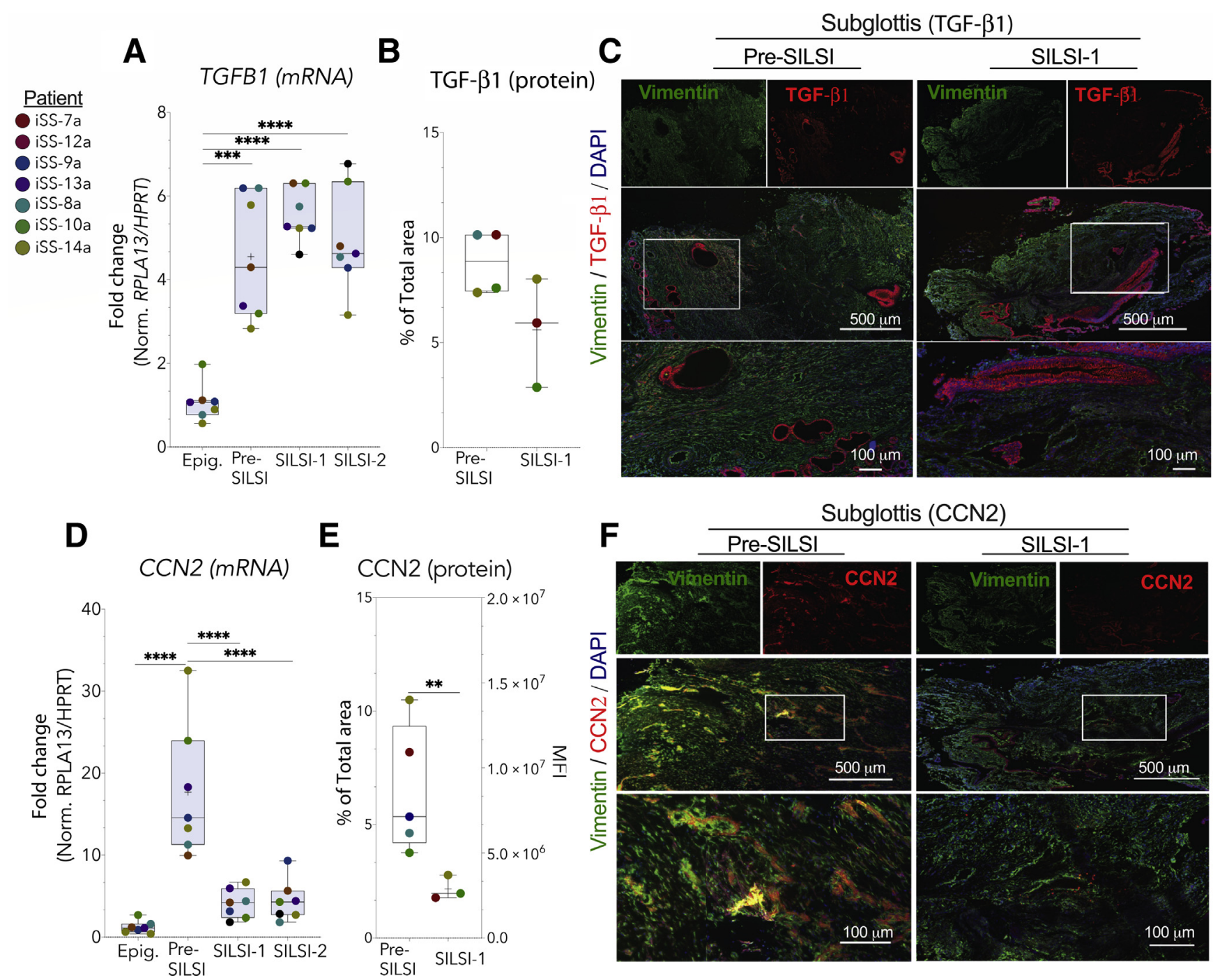

\section{$\mathbf{E}$}
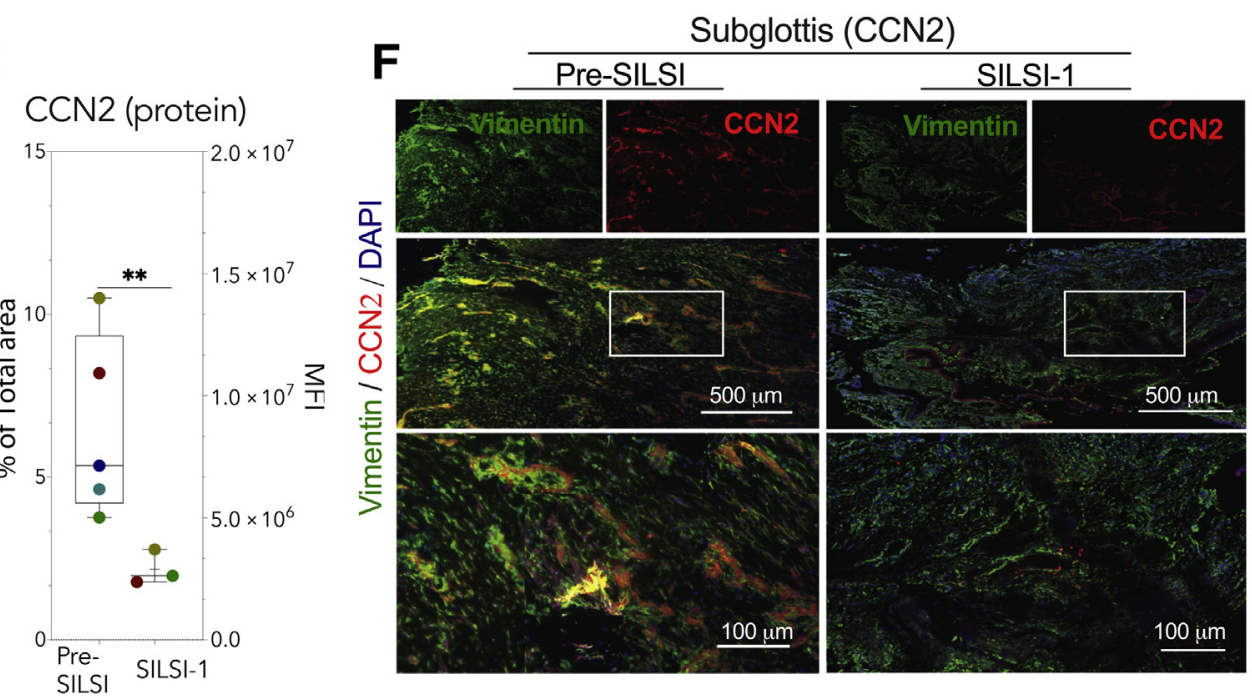

Figure 6 Serial intralesional steroid injection SILSI) improves fibrosis in idiopathic subglottic stenosis (iSGS) by down-regulating cellular communication network factor 2 (CCN2) expression, independently of transforming growth factor (TGF)- $\beta 1$. A: TGF $\beta 1$ mRNA [two-tailed, one-way analysis of variance (ANOVA) with Tukey test]. B: Percentage of tissue expressing TGF- $\beta 1$ analyzed by confocal microscopy (two-tailed, paired parametric $t$-test). C: Representative confocal microscopy image of the subglottis of a patient with iSGS labeled against vimentin (green), TGF- $\beta 1$ (red), and DAPI (blue). The uppermost micrographs correspond to single-channel micrographs showing TGF- $\beta 1$ (red) and vimentin (green) expression. The white boxed areas delineate regions of the subglottic stroma magnified for better visualization in the micrographs below. D: CCN2 mRNA (two-tailed, one-way ANOVA with Tukey test). E: Percentage of tissue expressing CCN2, analyzed by confocal microscopy (two-tailed, paired parametric $t$-test). F: Representative confocal microscopy image of the subglottis of a patient with iSGS labeled against vimentin (green), CCN2 (red), and DAPI (blue). The uppermost micrographs in the panel correspond to single-channel micrographs showing CCN2 (red) and vimentin (green) expression. The white boxed areas delineate regions of the subglottic stroma magnified for better visualization in the micrographs below. Data are expressed as means \pm SD (A, B, D, and $\mathbf{E}) . n=7$ (A and $\mathbf{B}$, SILSI- 1$) ; n=5$ (B, pre-SILSI); $n=5$ to 7 (E). ${ }^{* *} P<0.01,{ }^{* * *} P<0.001$, and ${ }^{* * * *} P<0.0001$. Scale bars: $500 \mu \mathrm{m}$ ( $\mathbf{C}$ and $\mathbf{F}$, white boxed areas); $100 \mu \mathrm{m}$ ( $\mathbf{C}$ and $\mathbf{F}$, bottom panels). Epig., epiglottis; Norm., normalized.

(baseline PEF $\%=45 \%$ to SILSI-2 PEF $\%=91 \%$; $P=0.001$ ) (Figure 4, B and C, and Table 3).

Steroids repress the production of a myriad of proinflammatory/profibrotic cytokines involved in fibrosis, which can itself be explanatory of the benefits conferred by SILSI in iSGS patients. Changes in the levels of $I L 1 B, T N F \alpha, I L 18$, and IL16 mRNA expression before and during SILSI as they coordinate distinct steps known to drive fibrosis, like fibroblast and inflammatory cell recruitment, inflammasome activation, ${ }^{31}$ and matrix production and induction of TGF- $\beta 1,{ }^{32}$ as is observed with tumor necrosis factor- $\alpha .{ }^{33}$ Compared with their control epiglottic tissue and their pretreatment specimen, the levels of $I L 1 B$ mRNA gene expression increased significantly during SILSI treatment (Figure 4D). IL16 mRNA levels, on the other hand, were significantly reduced compared with their control-matched epiglottic samples and their pre-SILSI sample (Figure 4D). Intriguingly, no changes in tumor necrosis factor- $\alpha$ or IL-18 occurred either during iSGS or as a result of steroid treatment (Figure 4D). These results argue against a role of steroids in controlling proinflammatory cytokines as the main mechanism underlying the clinical benefits of SILSI in iSGS. 

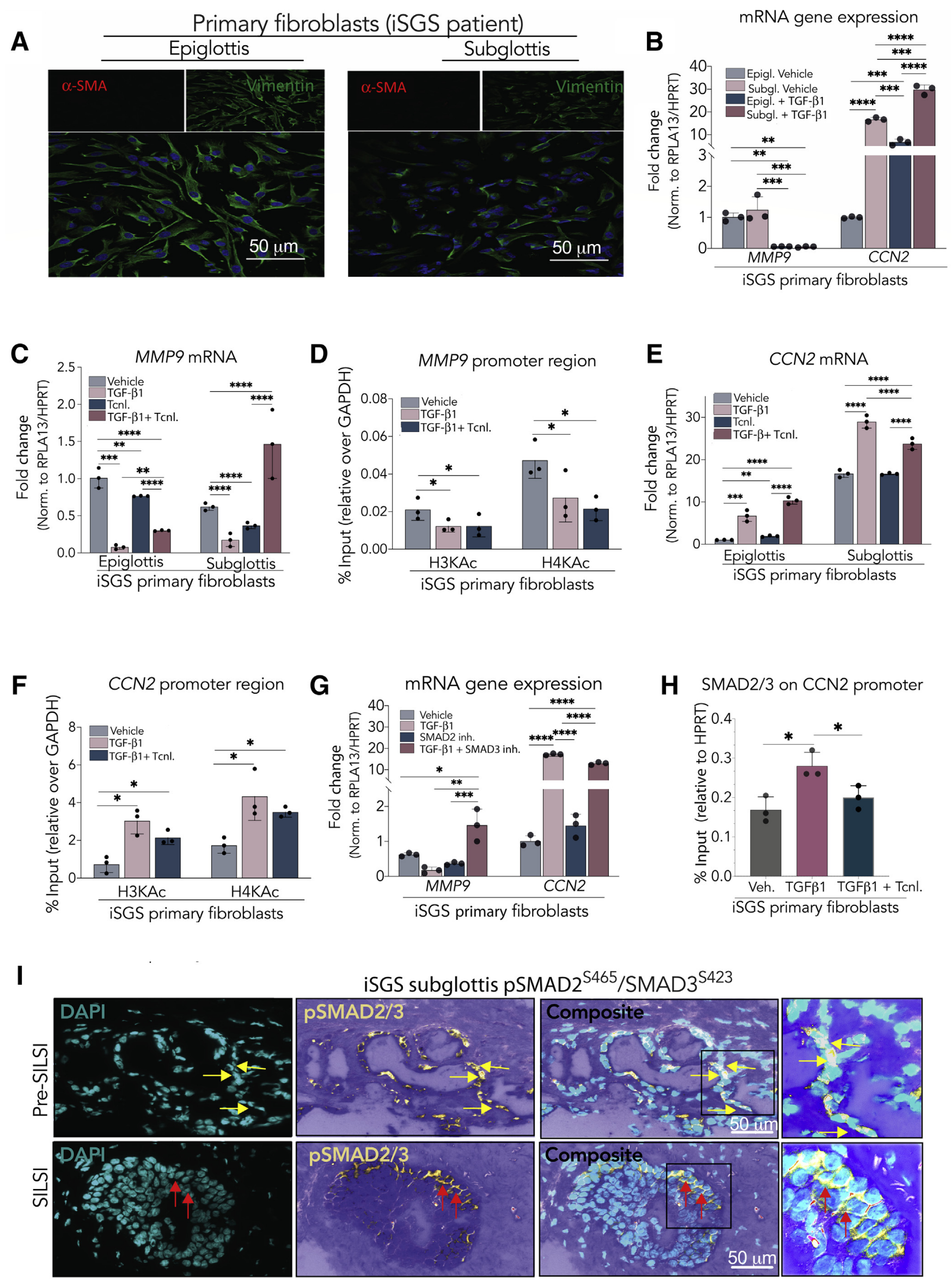
SILSI Modifies the Fibroblast Response and the Extracellular Matrix Remodeling Capacity of the Subglottis in iSGS

Despite SILSI's significant inhibition in scarring, which prevented us from obtaining large biopsy samples after the second office visit, we were able to compare the subglottic histology before and during SILSI treatments. Hematoxylin and eosin staining revealed that SILSI treatment generated important changes in the subglottic stroma. The clusters of inflammatory lymphoid cells observed in pre-SILSI samples (Figure 1A) were not evident following SILSI (Figure 5A). Also, the stroma developed thick fibrous cord bundles, which were arranged in an irregular manner throughout the subglottic stroma (Figure 5A). The fibrous cords contained numerous vimentin-positive, $\alpha-\mathrm{SMA}^{-} \quad$ fibroblasts (Figure 5B). However, overall, the number of fibroblasts reduced significantly in the subglottises of iSGS patients as a result of SILSI (Figure 5B).

Masson trichrome staining was used to visualize collagen deposition, which was arranged in cord-like structures in a similar manner to the fibroblasts (Figure 5C). mRNA analysis before and after two steroid injections revealed that subglottic COL1A1 mRNA expression levels remained high and unchanged with respect to their own subglottis before SILSI treatment (Figure 5D). COL6Al and fibronectin 1 mRNA levels trended higher in SILSI-treated tissue but did not reach significance with respect to their own subglottic pre-SILSI baseline (Figure 5, D and E). Overall, SILSI did not decrease the expression levels of genes involved in ECM synthesis, indicting their necessity for healing and possibly pointing to ECM remodeling as a potential pathway for iSGS disease modification.

$M M P 1$ mRNA expression remained unchanged with SILSI treatment, compared with that of baseline subglottis (Figure 5E). MMP2 gene expression levels were reduced after one steroid injection but did not reach statistical significance (Figure 5E). In contrast, SILSI treatment stimulated a highly significant induction of MMP9 levels, which reached on average 500-fold compared with their normal epiglottic samples and their own pre-SILSI control (Figure 5E). Together, the results indicate that stimulation of ECM production and remodeling are key aspects of the antifibrotic response conferred by SILSI.

\section{A Reduction in CCN2 but Not TGF- $\beta 1$ Levels Characterizes the Antifibrotic Response to SILSI}

The levels of TGFB1 mRNA gene expression were measured in the subglottic samples from the patients before and during SILSI and no correlation was found between the clinical improvement conferred by the steroids and a reduction in the levels of this profibrotic mediator. In fact, the levels of $T G F \beta 1$ remained high during SILSI, exhibiting similar expression levels as of baseline (Figure 6A). The lack of change in TGF- $\beta 1$ by SILSI was confirmed at the protein level using confocal microscopy (Figure 6, B and C). Confocal microscopy was also used to observe regions of TGF- $\beta 1$ induction concentrated in epithelial layers of the mucosa, which might reflect a normal induction required to stimulate re-epithelization in response to the tissue resection performed initially (Figure 6C). ${ }^{13}$ In contrast, with SILSI, the levels of CCN2 mRNA expression immediately decreased to levels of expression statistically similar to the epiglottic controls and never increased again (Figure 6D). Immunofluorescence staining confirmed the significant reduction of $\mathrm{CCN} 2$ expression, as noted by reduced percentage area positive for $\mathrm{CCN} 2$, as well as $\mathrm{CCN} 2$ mean fluorescence intensity (Figure 6, E and F). Collectively, these results suggest that SILSI improves fibrosis in iSGS by comodulating CCN2 and MMP9 levels, independently of TGF- $\beta 1$.

\footnotetext{
Figure 7 Serial intralesional steroid injection SILSI interferes with the coregulatory effect of transforming growth factor (TGF)- 31 on CCN2 and MMP9 expression. A: Representative confocal images of primary fibroblasts isolated from the subglottis or the epiglottis of the same patient with idiopathic subglottic stenosis (iSGS). Cells were labeled for $\alpha$-smooth muscle actin ( $\alpha$-SMA; red), vimentin (green), and DAPI (blue) for nuclear visualization. B: $C C N 2$ and MMP9 mRNA gene expression analysis in primary fibroblasts treated for 24 hours with vehicle [dimethyl sulfoxide (DMSO)] or $100 \mathrm{ng} / \mathrm{mL}$ of TGF- $\beta 1$. Experiment performed on three separate occasions with similar results. The graph corresponds to a representative experiment (one-way analysis of variance (ANOVA) with Sidak multiple-comparison test; statistics from all of the groups compared are shown]. C: MMP9 gene expression analysis in primary fibroblasts treated as in B (analysis performed per fibroblast subset, using one-way ANOVA with Tukey test). D: Chromatin immunoprecipitation (ChIP)-RT-qPCR analysis of histone acetylation of the promoter region of MMP9 (experiment performed in duplicate; analysis with one-way ANOVA with Tukey test). E: CCN2 gene expression analysis in primary fibroblasts treated with vehicle (DMSO), TGF- $\beta 1(100 \mathrm{nmol} / \mathrm{L})$, triamcinolone $(1 \mathrm{mg} / \mathrm{mL})$, or a combination of both for 24 hours (analysis performed per fibroblast subset, using one-way ANOVA with Tukey test). F: ChIP-RT-qPCR analysis of histone acetylation of the promoter region of CCN2 (experiment performed in duplicate; analysis with one-way ANOVA with Tukey test). G: MMP9 and CCN2 mRNA levels in primary iSGS-derived fibroblasts treated with vehicle (DMS0), recombinant human transforming growth factor beta-1 $(100 \mathrm{ng} / \mathrm{mL})$, the SMAD3 inhibitor SIS3 $(10 \mu \mathrm{mol} / \mathrm{L})$, or a combination of both (one-way ANOVA with Sidak multiple-comparison test; statistics from all of the groups compared are shown). H: ChIP-RT-qPCR analysis of SMAD2/3 (clone $138 D 4)$ binding to the $C C N 2$ promoter region in the presence of TGF- $\beta 1(100 \mathrm{nmol} / \mathrm{L})$ or a combination of triamcinolone $(1 \mathrm{mg} / \mathrm{mL})$ and TGF- $\beta 1$ (experiment performed in duplicate two times; analysis with one-way ANOVA with Tukey test). I: Representative confocal microscopy images showing the localization and expression of SMAD2/3 (fire) in or around the nucleus (DAPI; cyan) or cytoplasm of cells in the subglottis of patient before (pre-SILSI) or after one injection of steroids (SILSI-1). The black boxed areas show a region magnified in the images shown on the right. The yellow arrows in the micrographs above (pre-SILSI) point to regions exhibiting a nuclear pattern of phosphorylated SMAD2/3 (pSMAD2/3)-positive staining. Red arrows in the micrographs below (SILSI-1) shows cells with a perinuclear pattern of pSMAD2/3 staining. Data are expressed as means \pm SD $(\mathbf{B}-\mathbf{H}) . n=3$ replicates $(\mathbf{B}$ and $\mathbf{G}) ; n=3(\mathbf{C}$ and $\mathbf{E}) ; n=3$ per experiment (D and $\mathbf{F})$. ${ }^{*} P<0.05,{ }^{* *} P<0.01,{ }^{* *} P<0.001$, and ${ }^{* * * *} P<0.0001$. Scale bar $=50 \mu \mathrm{m}(\mathbf{A}$ and $\mathbf{I})$. Norm., normalized.
} 
Triamcinolone Prevents the Coregulation of $\mathrm{CCN} 2$ and MMP9 mRNA Expression Induced by TGF- $\beta 1$ in Primary Fibroblasts from an iSGS Patient

Primary fibroblasts were isolated from the subglottis and the unaffected epiglottis of the same patient with iSGS and used to model, in vitro, the effect of SILSI in modifying the coregulation of $C C N 2$ and $M M P 9$ gene expression by TGF$\beta 1$. No obvious morphologic differences were seen between subglottic and epiglottic fibroblasts, as they both expressed the same $\alpha$-SMA ${ }^{-} /$vimentin-positive phenotype observed in the fibroblasts located in the subglottises of iSGS patients (Figure 7A).

Treatment with TGF- $\beta 1$ induced a significant upregulation of CCN2 mRNA while simultaneously suppressing the levels of $M M P 9 \mathrm{mRNA}$ in both subglottic and epiglottic fibroblasts (Figure 7B). The changes in gene expression induced by TGF- $\beta 1$ followed a particular pattern of histone lysine acetylation. Specifically, TGF- $\beta 1$ induced a significant increase in the levels of histone 3 (H3KAc) and histone 4 (H4KAc) lysine acetylation at the $C C N 2$ promoter region, which correlated with the subsequent increase in its transcript levels (Figure 7, B-D). Conversely, TGF- $\beta 1$ decreased the overall levels of H3KAc and H4KAc in the promoter of the $M M P 9$ gene, correlating with a reduction in the transcript levels of this gene (Figure 7, E and F). Notably, triamcinolone reversed the suppressive effect of TGF- $\beta 1$ on $M M P 9$ mRNA levels, and prevented partially, yet significantly, the induction of $C C N 2$ mRNA induced by TGF- $\beta 1$, but only in the fibroblasts that derived from the subglottises of iSGS patients (Figure 7, C and E). However, triamcinolone exerted no effect in the overall pattern of histone lysine acetylation induced by TGF- $\beta 1$ signaling (Figure 7, D and F). This result indicates that the effect of this steroid in preventing the coregulation of $\mathrm{CCN} 2$ and $M M P 9$ gene expression induced by TGF- $\beta 1$ occurs independently from the changes in the epigenome that otherwise are induced by this profibrotic factor.

\section{Triamcinolone Modulates SMAD2/3 Promoter Binding Capacity in Response to TGF- $\beta 1$ Stimulation}

The effect of SMAD signaling in driving the changes in $M M P 9$ and $C C N 2$ expression observed during TGF- $\beta 1$ treatment were studied. Using chromatin immunoprecipitation coupled with RT-PCR, it was confirmed that stimulation with TGF- $\beta 1$ led to the binding of SMAD2/3 to the promoter region of $C C N 2$ (Figure $7 \mathrm{G}$ ). Interestingly, inhibition of SMAD2/3 phosphorylation with SIS3 reversed the inhibitory effect of TGF- $\beta 1$ on $M M P 9$ gene expression and prevented partially but significantly the levels of induction of CCN2 mRNA, in a manner reminiscent of what was observed with triamcinolone treatment (Figure 7H). Indeed, triamcinolone treatment reduced the binding capacity of SMAD2/3 to the CCN2 promoter region, potentially explaining the mitigation of the induction of this gene in response to TGF- $\beta 1$ signaling (Figure $7 \mathrm{G}$ ). Finally, the subglottises of iSGS patients were evaluated before and after SILSI for evidence of changes in SMAD2/3 nuclear localization, resulting from exposure to this steroid. Strikingly, colocalization of phosphorylated SMAD2/3 in the nucleus was more frequent in the subglottises of patients before SILSI, whereas after SILSI, the more frequent pattern of expression was cytosolic/perinuclear, denoting a decrease in nuclear localization (Figure 7I).

\section{Discussion}

A course of SILSI, consisting of six injections, achieves comparable results to surgery in reversing iSGS stenosis without the need for surgery. ${ }^{6}$ SILSI has been adopted by many medical centers around the world ${ }^{5}$ and is challenging the therapeutic paradigm of iSGS, from a surgical disease that requires interventions, like frequent dilations, laryngotracheoplasty, or cricotracheal resection, ${ }^{34-36}$ to a potentially medically treated disease. Herein, the beneficial effects of steroids on fibrosis were used as a model to identify steroid-sensitive pathways potentially implicated in iSGS development.

Several aspects of this study warrant special consideration. First, and to the best of our knowledge, this study provided the most comprehensive histopathologic description of iSGS thus far. It reports a complete histologic description of the normal subglottis, emphasizing how the abnormal deposition of ECM and the severe fibroblastic and inflammatory infiltrative process in iSGS destroy it. The alteration of the continuum of the mucosa, and the pronounced alteration of the several stromal components, such as epithelial and glandular metaplasia, vasculitis, and glandular necrosis, might explain some key clinical symptoms that affect iSGS patients.

Second, this study described the ECM composition and characterized the type of stromal fibroblasts that predominate in iSGS. It is puzzling that iSGS, characterized by high levels of TGF- $\beta 1$, is not dominated by $\alpha$ $\mathrm{SMA}^{+}$myofibroblasts. This cell type is considered a terminally differentiated fibroblast subset, whose transdifferentiation depends on TGF- $\beta 1$-dependent signaling. ${ }^{37}$ Nonetheless, the process of differentiation occurs in two steps and involves an intermediate differentiation step that generates a cell type known as a proto-myofibroblast ${ }^{38}$ that produces large amounts of fibronectin and the alternativespliced form of fibronectin extradomain-A before expressing $\alpha$-SMA. ${ }^{38}$ The finding showing high levels of fibronectin mRNA expression in the subglottises of iSGS potentially indicates the presence of proto-myofibroblasts and their involvement in the iSGS fibrotic response. Although the presence of vimentin-positive, $\alpha-\mathrm{SMA}^{-}$fibroblasts in the subglottic stroma was consistently observed in multiple patients, staining for ED-A was not performed, 
so a conclusive identification and evaluation of protomyofibroblasts as key cell subsets awaits further evaluation.

Third, this study identified pericytes as a potential cell of interest in the development of iSGS. Pericytes express several markers, including platelet-derived growth factor receptor $\beta$, CD146, neural/glial antigen 2 , and $\alpha$-SMA, but lack the expression of leukocytic antigens, such as CD45, and do not express CD31. ${ }^{34,40}$ Herein, an $\boldsymbol{\alpha}$-SMA ${ }^{+} /$vimentin-negative/ $\mathrm{CD} 31^{-}$perivascular cell population, consistent with pericytes, was identified as one of the main producers of both CCN2 and TGF- $\beta 1$ during iSGS. In normal conditions, pericytes maintain the vascular integrity and participate in the formation of specialized vascular structures, like the bloodbrain barrier. However, ample lines of evidence ${ }^{39,40}$ indicate that pericytes have a particular plasticity to differentiate into fibroblasts and myofibrillar fibroblasts, which, in turn, contribute to the development of several fibrotic diseases, such as kidney fibrosis, spinal cord fibrosis, and cardiac fibrosis, among others. ${ }^{41-44}$ It is possible that the strong immunoreactivity to CCN2 and TGF- $\beta 1$ observed in these cells is a reflection that these cells are active players that respond to a yet unknown signal to release mediators and exacerbate the disease. Further research must be conducted to address the role of pericytes in iSGS.

Fourth, this study provided important molecular insights into the mechanistic aspects underlying iSGS development. Central to this study was the analysis of TGF- $\beta 1$, which was consistently up-regulated in the subglottis of our patients and, as deduced from the in vitro studies, stimulates a gene expression program that recapitulates many of the profibrotic events observed in the subglottis of iSGS patients. A remarkable finding was the compartmentalized distribution of TGF- $\beta 1$ expression, which was specifically located in vimentin-positive, $\alpha$-SMA ${ }^{+}$perivascular cells, phenotypically resembling pericytes, ${ }^{45}$ and in mucus gland epithelial cells. Surrounding these structures were numerous fibroblasts that displayed a strong immunoreactivity for CCN2. This pattern of expression founded our hypothesis that a potential paracrine axis might drive $\mathrm{CCN} 2$ expression by stromal fibroblasts in response to the TGF- $\beta 1$ produced by the glandular epithelial cells. Indeed, this model of CCN2 production was confirmed in our in vitro studies. These studies confirmed that TGF- $\beta 1$ suppresses MMP9 expression in primary fibroblasts, potentially explaining a reduction in ECM remodeling and consequently an accumulation of these proteins in the stroma of the subglottises of iSGS patients. According to previous reports, $\mathrm{CCN} 2$ plays an important role in the establishment of other idiopathic fibrotic diseases, ${ }^{23,27}$ making it a candidate for neutralization as a means to treat several fibrotic diseases. ${ }^{46}$ Together, we conclude that an axis involving TGF- $\beta 1 / \mathrm{CCN} 2$ expression is important in driving part of the pathology observed in iSGS.

Surprisingly, SILSI did not reduce the subglottic levels of TGF- $\beta 1$ expression. Sustained high levels of the TGF- $\beta 1$ target genes collagen I and VI and fibronectin were observed even during SILSI treatment. Nonetheless, the appearance of ECM cords evidenced by cytochemical staining methods indicates that ECM remodeling, rather than ECM production, is potentially the key element contributing to the reduction of fibrosis in iSGS in response to SILSI. Supporting this theory, the levels of MMP9 expression increased significantly (500-fold) in iSGS subglottis in response to SILSI. Together with the in vitro data showing that steroid treatment reverses the inhibitory action of TGF- $\beta 1$ on MMP9 expression, we conclude that SILSI is enabling ECM remodeling by interrupting the inhibitory effect of TGF- $\beta 1$ on MMP9 expression.

SILSI reduced the number of subglottic vimentinpositive stromal fibroblasts. This effect cannot be explained by changes in TGF- $\beta 1$ because, as mentioned, it remained high despite steroid treatment. Remarkably, however, SILSI significantly reduced the levels of expression of CCN2 starting with the first steroid injection. The in vitro studies demonstrated that steroid treatment of subglottic fibroblasts prevented in a significant, albeit incomplete, manner the induction of CCN2 in response to TGF- $\beta 1$. These in vitro studies were conducted using triamcinolone, a suspension where the steroid forms precipitates that require the action of tissue esterases to fully make it available. It is possible that the incomplete effect obtained is due to the chemical nature of triamcinolone in culture, or differences in timing or dosage that could improve the effect obtained. Nevertheless, the current results support a model in which steroids prevent $\mathrm{CCN} 2$ expression by inhibiting the induction capacity of TGF- $\beta 1$ downstream of the TGF- $\beta$ receptor. Together with a similar mechanism of derepression of MMP9, we propose that steroids improve iSGS by facilitating MMP9 matrix remodeling and by reducing the effects of connective tissue growth factor on fibroblast recruitment, proliferation, and differentiation.

Mechanistically, this study provided insight into a potential way by which steroids interrupt the coregulation of MMP9 and CCN 2 by TGF- $\beta 1$. As shown, TGF- $\beta 1$ triggered important changes in the histone acetylation status at nucleosomes located in promotor regions of genes relevant for fibrosis. TGF- $\beta 1$ is known to affect histone acetylation by recruiting histone acetyltransferases, like CREB binding protein/p300. ${ }^{47,48}$ Recruitment of this histoneacetyltransferase complex coordinates gene expression through several mechanisms. First, it can modify posttranscriptionally directed key transcriptions, like SMADs, altering their activity. ${ }^{49}$ Alternatively, it can regulate histone acetylation directly, modifying the accessibility of promotor regions to transcription factors. ${ }^{50}$ In the current experiments, an increase in $\mathrm{H} 3 \mathrm{KAc}$ and $\mathrm{H} 4 \mathrm{KAC}$ in the promoter of CCN2 tracked with the concomitant induction of this gene, whereas a reduction in the acetylation levels of these histones in the $M M P 9$ gene promoter tracked with a reduction in the levels of expression of this transcript. The clinical significance of these results stands alone because they are an indication of the possibility of using histone 
acetyltransferase inhibitors to treat fibrosis. Although, to date, no histone deacetylase inhibitor has reached US Food and Drug Administration approval status, recent evidence provides proof for this concept by showing that a selective p300 inhibitor can ameliorate fibrosis in a bleomycininduced model. ${ }^{50}$ Similarly, plumbagin, which was shown to be an inhibitor of p300, suppresses fibrosis in an idiopathic pulmonary fibrosis model. ${ }^{51}$

However, these data do not support a role of steroids, specifically triamcinolone, in counterregulating the effects of TGF- $\beta 1$ by impacting the histone epigenome. In fact, although the role of triamcinolone as an antifibrotic agent has been recognized for decades, a fully detailed mechanism underlying this widely accepted effect remains elusive. There have been attempts to detail this in various models, ranging from normal dermal fibroblasts ${ }^{52,53}$ to keloids (idiopathic carpal tunnel ${ }^{53,54}$ ), among others. Interestingly, the only correlation consistently reported is that triamcinolone decreases the levels of TGF- $\beta 1$ in those models. ${ }^{52,53}$ These results are strikingly different from ours because, in this study, triamcinolone did not modify the levels of TGF- $\beta 1$, yet it achieved counterregulation of the altered profibrotic axis involving MMP9 and CCN2, that is controlled by TGF- $\beta 1$ signaling. The results provide a potential explanation that involves triamcinolone counteracting the profibrotic stimulus of TGF- $\beta 1$ downstream of the receptor at the level of SMAD2/3 binding to the promotor regions. A similar mechanism of counterregulation of gene expression by triamcinolone has not been reported. However, functional studies involving site mutagenesis, coprecipitation, or direct interrogation, looking for an interaction between steroidal signaling and SMAD binding were not performed. Therefore, these results must be considered observational until further research conclusively proves the existence of the way triamcinolone blocks fibrosis in the subglottises of iSGS patients.

There are several limitations to this study. First, a total of seven patients were included, and although the data obtained were highly reproducible, it would be advantageous to increase the size of the cohort. Second, the epiglottis was used as a control for iSGS. The rationale was that the epiglottis of patients with iSGS is unaffected, while still being part of the same organ close to the affected area. Indeed, the expression of fibrotic genes was significantly lower compared to their patient-matched subglottic tissue. Nevertheless, the histologic features of the epiglottis differ from those of the subglottis, and normal subglottic samples would better serve as controls.

A third limitation is the limited number of biopsies that were possible in any one patient. Only specimens from immediately before to the first to third SILSI administration were analyzed, so it is not possible to assert whether the changes described are sustained or accelerate with more SILSI treatments. A fourth limitation relates to the amount of sample that is possible to obtain during SILSI. As mentioned, SILSI induces a drastic reduction in fibrosis, and it is not possible to obtain large enough pieces for adequate histologic examination after the second or third injection. This is why only three small SILSI-1 samples were obtained, limiting the quality of histology. A fifth limitation relates to the in vitro studies. As mentioned, only one set of patient-matched epiglottis was included, pre-SILSI and SILSI-1 fibroblasts. It is ideal to expand these studies utilizing more cell lines generated from multiple patients. The last limitation relates to the scope of the study. The investigation was limited to explore the role of a particular pathway (namely, TGF- $\beta 1, \mathrm{CCN} 2$, and ECM remodeling as the targets of SILSI).

It is important to acknowledge that steroids have a broad and pleiotropic mode of action, affecting other systems, particularly the immune system. iSGS displays mild chronic inflammation, so it is likely that besides what is presented herein, SILSI also regulates key inflammatory aspects of the disease, such as the IL-17-type 17 helper T-cell axis, ${ }^{54}$ that together with the described effect on $\mathrm{CCN} 2$ translates into the overall improvement of the disease seen clinically. Nonetheless, this work provides important novel insights into the mechanism of iSGS development and how SILSI works. This work is also evidence that the strong clinical effect achieved by steroid treatment can be exploited as a tool to continue the discovery of key aspects involved in the pathogenesis of iSGS. Further studies with SILSI-treated patients can expand our knowledge of the disease to enable the discovery of novel pathways that can be modulated to aid the treatment of those who are steroid resistant, or to understand the general mechanisms of fibrosis development that can be extrapolated to additional disease states.

\section{Acknowledgments}

This article is dedicated in your loving memory, you were our most beloved friend, the keenest mentor, and the most brilliant scientist. Thank you for everything Jay, you impacted on the life of many, and we will miss you. We thank Dr. James R. Mitchell, for offering his laboratory for research, Peter Sadow, MD, for guidance with histopathology; and the Microscopy Resources in the North Quad and, specially, Paula De la Milagrosa Montero, PhD, for her knowledge, skills, and willingness to train and teach us on the advanced microscopy techniques used in this work. We also thank our patients, who have idiopathic subglottic stenosis and who, through their generosity of spirit, willingly participated in this study. Their struggle to breathe was the impetus to discover serial intralesional steroid injections to improve their care and continues to propel us.

Funding: This work was supported by donations from Deborah Thornton.

\section{References}

1. Valdez TA, Shapshay SM: Idiopathic subglottic stenosis revisited. Ann Otol Rhinol Laryngol 2002, 111:690-695 
2. Jazbi B, Goodwin C, Tackett D, Faulkner S: Idiopathic subglottic stenosis. Ann Otol Rhinol Laryngol 1977, 86:644-648

3. Park SS, Streitz JM Jr, Rebeiz EE, Shapshay SM: Idiopathic subglottic stenosis. Arch Otolaryngol Head Neck Surg 1995, 121: 894-897

4. Andrews JP, Marttala J, Macarak E, Rosenbloom J, Uitto J: Keloids: the paradigm of skin fibrosis - pathomechanisms and treatment. Matrix Biol 2016, 51:37-46

5. Hoffman MR, Coughlin AR, Dailey SH: Serial office-based steroid injections for treatment of idiopathic subglottic stenosis. Laryngoscope 2017, 127:2475-2481

6. Franco RA Jr, Husain I, Reder L, Paddle P: Awake serial intralesional steroid injections without surgery as a novel targeted treatment for idiopathic subglottic stenosis. Laryngoscope 2018, 128:610-617

7. Kraft SM, Sykes K, Palmer A, Schindler J: Using pulmonary function data to assess outcomes in the endoscopic management of subglottic stenosis. Ann Otol Rhinol Laryngol 2015, 124:137-142

8. Naunheim MR, Paddle PM, Husain I, Wangchalabovorn P, Rosario D, Franco RA Jr: Quality-of-life metrics correlate with disease severity in idiopathic subglottic stenosis. Laryngoscope 2018, 128:1398-1402

9. Biernacka A, Dobaczewski M, Frangogiannis NG: TGF-beta signaling in fibrosis. Growth Factors 2011, 29:196-202

10. Meng X-m, Nikolic-Paterson DJ, Lan HY: TGF- $\beta$ : the master regulator of fibrosis. Nat Rev Nephrol 2016, 12:325

11. White ES, Mantovani AR: Inflammation, wound repair, and fibrosis: reassessing the spectrum of tissue injury and resolution. J Pathol 2013, 229:141-144

12. Gressner AM, Weiskirchen R, Breitkopf K, Dooley S: Roles of TGFbeta in hepatic fibrosis. Front Biosci 2002, 7:d793-807

13. Ramirez H, Patel SB, Pastar I: The role of TGFbeta signaling in wound epithelialization. Adv Wound Care (New Rochelle) 2014, 3: 482-491

14. Zinski J, Tajer B, Mullins MC: TGF-beta family signaling in early vertebrate development. Cold Spring Harb Perspect Biol 2018, 10: a033274

15. Lyons RM, Keski-Oja J, Moses HL: Proteolytic activation of latent transforming growth factor-beta from fibroblast-conditioned medium. J Cell Biol 1988, 106:1659-1665

16. Lyons RM, Gentry LE, Purchio AF, Moses HL: Mechanism of activation of latent recombinant transforming growth factor beta 1 by plasmin. J Cell Biol 1990, 110:1361-1367

17. Vander Ark A, Cao J, Li X: TGF-beta receptors: in and beyond TGFbeta signaling. Cell Signal 2018, 52:112-120

18. Zhang Y, Alexander PB, Wang XF: TGF-beta family signaling in the control of cell proliferation and survival. Cold Spring Harb Perspect Biol 2017, 9:a022145

19. Sun YB, Qu X, Caruana G, Li J: The origin of renal fibroblasts/myofibroblasts and the signals that trigger fibrosis. Differentiation 2016, 92:102-107

20. Yuan W, Varga J: Transforming growth factor-beta repression of matrix metalloproteinase-1 in dermal fibroblasts involves Smad3. J Biol Chem 2001, 276:38502-38510

21. Ogawa K, Chen F, Kuang C, Chen Y: Suppression of matrix metalloproteinase- 9 transcription by transforming growth factor-beta is mediated by a nuclear factor-kappaB site. Biochem $\mathrm{J} 2004,381$ : $413-422$

22. Verrecchia F, Mauviel A: Transforming growth factor-beta signaling through the Smad pathway: role in extracellular matrix gene expression and regulation. J Invest Dermatol 2002, 118:211-215

23. Kinashi H, Falke LL, Nguyen TQ, Bovenschen N, Aten J, Leask A, Ito $\mathrm{Y}$, Goldschmeding R: Connective tissue growth factor regulates fibrosis-associated renal lymphangiogenesis. Kidney Int 2017, 92: $850-863$

24. Shi-Wen X, Leask A, Abraham D: Regulation and function of connective tissue growth factor/CCN2 in tissue repair, scarring and fibrosis. Cytokine Growth Factor Rev 2008, 19:133-144
25. Xu H, Li P, Liu M, Liu C, Sun Z, Guo X, Zhang Y: CCN2 and CCN5 exerts opposing effect on fibroblast proliferation and transdifferentiation induced by TGF-beta. Clin Exp Pharmacol Physiol 2015, 42:1207-1219

26. Mezzano V, Cabrera D, Vial C, Brandan E: Constitutively activated dystrophic muscle fibroblasts show a paradoxical response to TGFbeta and CTGF/CCN2. J Cell Commun Signal 2007, 1:205-217

27. Chen MM, Lam A, Abraham JA, Schreiner GF, Joly AH: CTGF expression is induced by TGF-beta in cardiac fibroblasts and cardiac myocytes: a potential role in heart fibrosis. J Mol Cell Cardiol 2000, 32:1805-1819

28. Rayego-Mateos S, Morgado-Pascual JL, Rodrigues-Diez RR, Rodrigues-Diez R, Falke LL, Mezzano S, Ortiz A, Egido J, Goldschmeding R, Ruiz-Ortega M: Connective tissue growth factor induces renal fibrosis via epidermal growth factor receptor activation. J Pathol 2018, 244:227-241

29. Trevino-Villarreal JH, Reynolds JS, Bartelt A, Langston PK, MacArthur MR, Arduini A, Tosti V, Veronese N, Bertozzi B, Brace LE, Mejia P, Trocha K, Kajitani GS, Longchamp A, Harputlugil E, Gathungu R, Bird SS, Bullock AD, Figenshau RS, Andriole GL, Thompson A, Heeren J, Ozaki CK, Kristal BS, Fontana L, Mitchell JR: Dietary protein restriction reduces circulating VLDL triglyceride levels via CREBH-APOA5-dependent and -independent mechanisms. JCI Insight 2018, 3:1396

30. Song SA, Franco RA Jr: Serial intralesional steroid injection for subglottic stenosis. Laryngoscope 2020, 130:698-701

31. Iannitti RG, Napolioni V, Oikonomou V, De Luca A, Galosi C, Pariano M, Massi-Benedetti C, Borghi M, Puccetti M, Lucidi V, Colombo C, Fiscarelli E, Lass-Florl C, Majo F, Cariani L, Russo M, Porcaro L, Ricciotti G, Ellemunter H, Ratclif L, De Benedictis FM, Talesa VN, Dinarello CA, van de Veerdonk FL, Romani L: IL-1 receptor antagonist ameliorates inflammasomedependent inflammation in murine and human cystic fibrosis Nat Commun 2016, 7:10791

32. Kawabata K, Makino T, Makino K, Kajihara I, Fukushima S, Ihn H: IL-16 expression is increased in the skin and sera of patients with systemic sclerosis. Rheumatology (Oxford) 2020, 59:519-523

33. Sullivan DE, Ferris M, Nguyen H, Abboud E, Brody AR: TNF-alpha induces TGF-betal expression in lung fibroblasts at the transcriptional level via AP-1 activation. J Cell Mol Med 2009, 13 $1866-1876$

34. Ashiku SK, Kuzucu A, Grillo HC, Wright CD, Wain JC, Lo B, Mathisen DJ: Idiopathic laryngotracheal stenosis: effective definitive treatment with laryngotracheal resection. J Thorac Cardiovasc Surg 2004, 127:99-107

35. Grillo HC, Mark EJ, Mathisen DJ, Wain JC: Idiopathic laryngotracheal stenosis and its management. Ann Thor Surg 1993, 56: 80-87

36. Liberman M, Mathisen DJ: Treatment of idiopathic laryngotracheal stenosis. Semin Thorac Cardiovasc Surg 2009, 21:278-283

37. Hinz B, Phan SH, Thannickal VJ, Galli A, Bochaton-Piallat ML, Gabbiani G: The myofibroblast: one function, multiple origins. Am J Pathol 2007, 170:1807-1816

38. Hinz B: Formation and function of the myofibroblast during tissue repair. J Invest Dermatol 2007, 127:526-537

39. Armulik A, Genove G, Mae M, Nisancioglu MH, Wallgard E, Niaudet C, He L, Norlin J, Lindblom P, Strittmatter K, Johansson BR, Betsholtz C: Pericytes regulate the blood-brain barrier. Nature 2010, 468:557-561

40. Yamazaki T, Mukouyama YS: Tissue specific origin, development, and pathological perspectives of pericytes. Front Cardiovasc Med 2018, 5:78

41. Wu CF, Chiang WC, Lai CF, Chang FC, Chen YT, Chou YH, Wu TH, Linn GR, Ling H, Wu KD, Tsai TJ, Chen YM, Duffield JS, Lin SL: Transforming growth factor $\beta$-1 stimulates profibrotic epithelial signaling to activate pericyte-myofibroblast transition in obstructive kidney fibrosis. Am J Pathol 2013, 182:118-131 
42. Kramann R, Schneider RK, DiRocco DP, Machado F, Fleig S, Bondzie PA, Henderson JM, Ebert BL, Humphreys BD: Perivascular Gli1+ progenitors are key contributors to injury-induced organ fibrosis. Cell Stem Cell 2015, 16:51-66

43. Humphreys BD, Lin SL, Kobayashi A, Hudson TE, Nowlin BT, Bonventre JV, Valerius MT, McMahon AP, Duffield JS: Fate tracing reveals the pericyte and not epithelial origin of myofibroblasts in kidney fibrosis. Am J Pathol 2010, 176:85-97

44. Dias DO, Kim H, Holl D, Werne Solnestam B, Lundeberg J, Carlén M, Göritz C, Frisén J: Reducing pericyte-derived scarring promotes recovery after spinal cord injury. Cell 2018, 173:153-165.e22

45. Crisan M, Yap S, Casteilla L, Chen CW, Corselli M, Park TS, Andriolo G, Sun B, Zheng B, Zhang L, Norotte C, Teng PN, Traas J, Schugar R, Deasy BM, Badylak S, Buhring HJ, Giacobino JP, Lazzari L, Huard J, Peault B: A perivascular origin for mesenchymal stem cells in multiple human organs. Cell Stem Cell 2008, 3:301-313

46. Makino K, Makino T, Stawski L, Lipson KE, Leask A, Trojanowska M: Anti-connective tissue growth factor (CTGF/CCN2) monoclonal antibody attenuates skin fibrosis in mice models of systemic sclerosis. Arthritis Res Ther 2017, 19:134

47. Janknecht R, Wells NJ, Hunter T: TGF-beta-stimulated cooperation of smad proteins with the coactivators CBP/p300. Genes Dev 1998, 12:2114-2119

48. Feng XH, Zhang Y, Wu RY, Derynck R: The tumor suppressor Smad4/DPC4 and transcriptional adaptor CBP/p300 are coactivators for smad3 in TGF-beta-induced transcriptional activation. Genes Dev 1998, 12:2153-2163
49. Shen X, Hu PP, Liberati NT, Datto MB, Frederick JP, Wang XF: TGF-beta-induced phosphorylation of Smad3 regulates its interaction with coactivator p300/CREB-binding protein. Mol Biol Cell 1998, 9: 3309-3319

50. Hwang SY, Park SY, Hong JY, Lee SY, Shin JH, Na Y, Sohn MH, Yoon HG, Kwon Y: Field-based rational design of p300 histone acetyltransferase inhibitor and systematic evaluation as an antifibrotic agent. Chem Commun (Camb) 2020, 56:9795-9798

51. Lee SY, Kim MJ, Jang S, Lee GE, Hwang SY, Kwon Y, Hong JY, Sohn MH, Park SY, Yoon HG: Plumbagin suppresses pulmonary fibrosis via inhibition of $\mathrm{p} 300$ histone acetyltransferase activity. J Med Food 2020, 23:633-640

52. Yang TH, Gingery A, Thoreson AR, Larson DR, Zhao C, Amadio PC: Triamcinolone acetonide affects TGF- $\beta$ signaling regulation of fibrosis in idiopathic carpal tunnel syndrome. BMC Musculoskelet Disord 2018, 19:342

53. Carroll LA, Hanasono MM, Mikulec AA, Kita M, Koch RJ: Triamcinolone stimulates bFGF production and inhibits TGF-beta1 production by human dermal fibroblasts. Dermatol Surg 2002, 28: 704-709

54. Gelbard A, Katsantonis NG, Mizuta M, Newcomb D, Rotsinger J, Rousseau B, Daniero JJ, Edell ES, Ekbom DC, Kasperbauer JL, Hillel AT, Yang L, Garrett CG, Netterville JL, Wootten CT, Francis DO, Stratton C, Jenkins K, McGregor TL, Gaddy JA, Blackwell TS, Drake WP: Idiopathic subglottic stenosis is associated with activation of the inflammatory IL-17A/IL-23 axis. Laryngoscope 2016, 126:E356-E361 